\title{
WP 32_12
}

\author{
Paolo Paruolo \\ University of Insubria, Italy \\ The Rimini Centre for Economic Analysis (RCEA), Italy
}

Ben Murphy

European Commission, Joint Research Centre, Institute for Environment and Sustainability (IES), Italy

Greet Janssen-Maenhout

European Commission, Joint Research Centre, Institute for Environment and

Sustainability (IES), Italy

\section{DO EMISSIONS AND INCOME HAVE A COMMON TREND? A COUNTRY-SPECIFIC, TIME-SERIES, GLOBAL ANALYSIS, 1970- 2008}

Copyright belongs to the author. Small sections of the text, not exceeding three paragraphs, can be used provided proper acknowledgement is given.

The Rimini Centre for Economic Analysis (RCEA) was established in March 2007. RCEA is a private, nonprofit organization dedicated to independent research in Applied and Theoretical Economics and related fields. RCEA organizes seminars and workshops, sponsors a general interest journal The Review of Economic Analysis, and organizes a biennial conference: The Rimini Conference in Economics and Finance (RCEF) . The RCEA has a Canadian branch: The Rimini Centre for Economic Analysis in Canada (RCEACanada). Scientific work contributed by the RCEA Scholars is published in the RCEA Working Papers and Professional Report series.

The views expressed in this paper are those of the authors. No responsibility for them should be attributed to the Rimini Centre for Economic Analysis. 


\title{
DO EMISSIONS AND INCOME HAVE A COMMON TREND? A COUNTRY-SPECIFIC, TIME-SERIES, GLOBAL ANALYSIS, 1970-2008
}

\author{
PAOLO PARUOLO ${ }^{\natural}$, BEN MURPHY $^{\circ}$, AND GREET JANSSENS-MAENHOUT $^{\diamond}$
}

\begin{abstract}
This paper uses Vector Autoregressions that allow for nonstationarity and cointegration to investigate the dynamic relation between income and emissions in the period 1970-2008, for all world countries. We consider three emissions compounds, namely $\mathrm{CO}_{2}, \mathrm{SO}_{2}$ and a composite global warming index (GWP100). These emissions include energy-related activities with a share varying from $60 \%(\mathrm{GWP} 100)$ to almost $90 \%\left(\mathrm{SO}_{2}\right)$. For all chemical compounds, it is found that for over two thirds of cases income and emissions are driven by unrelated random walks with drift, at $5 \%$ significance level. For one quarter of the cases the variables are found to be driven by a common random walk with drift. Finally, for the remaining $4.5 \%$ of cases the variables are trend-stationary. Tests of Granger-causality show evidence of both directions of causality. For the case of unrelated stochastic trends, one finds a predominance of emissions causing income (in growth rates), which accords with a production-function rather than with a consumption-function interpretation of the emissions-income relation. The evidence challenges the main implications of the Environmental Kuznets Curve hypothesis, namely that the dominant direction of causality should be from income to emissions, and that for increasing levels of income, emissions should tend to decrease.
\end{abstract}

Date: November 15, 2011 JEL classification: Q53, Q54.

Key words and phrases. Environmental Kuznets Curve; Emissions; Income; Cointegration; Common trends. 七 Corresponding author, University of Insubria, Department of Economics, Via Monte Generoso 71, I-21100 Varese, Italy; tel: +390332395541, fax: +390332395509; email: paolo.paruolo@uninsubria.it.

- European Commission, Joint Research Centre, Institute for Environment and Sustainability, Via E. Fermi 2749, TP 290, I-21027 Ispra (VA), Italy. Present address: The Granary, West Lilling, North Yorkshire, England YO60 6RP, UK; email: benmichaelmurphy@gmail.com.

$\diamond$ European Commission, Joint Research Centre, Institute for Environment and Sustainability, Via E. Fermi 2749, TP 290, I-21027 Ispra (VA), Italy; email: greet.maenhout@jrc.ec.europa.eu. 


\section{Contents}

1. Introduction 1

2. Literature review 3

3. Econometric specification 5

4. Data 7

5. Empirical results 9

5.1. Choice of lag length 9

5.2. Cointegration rank 10

5.3. Level relations 12

5.4. Granger causality 15

6. Conclusions 18

$\begin{array}{ll}\text { Acknowledgements } & 19\end{array}$

$\begin{array}{ll}\text { References } & 19\end{array}$

Appendix 22

Datasets 22

Extra material: Additional tables 24 


\section{INTRODUCTION}

The emissions-income relation is important both in the prediction of emissions concentrations and in the mitigation/adaptation policy debate, see Stern (2006), IPCC (2007). The Environmental Kuznets Curve (EKC) hypothesis predicts that emissions follow and inverted U-shaped (or N-shaped) pathway as income rises ${ }^{1}$. This prediction is based on a consumption function interpretation of the emissions-income relation, where at higher levels of income, consumers are more willing to pay for environmental conservation.

The EKC hypothesis is widely used in scenarios and policy simulations, see e.g. the IPCC reports in Meehl et al. (2007) or in Chapter 3.1 of Nakićenović and Swart (2000). However, on the one hand, the statistical evidence on which the EKC is based is regarded by some as methodologically 'not robust', see Stern (2004) and Wagner (2008). Empirically, on the other hand, the EKC hypothesis has been evaluated using $\mathrm{CO}_{2}$ or $\mathrm{SO}_{2}$ emissions, which are mainly the result of energy-related activities. The current evidence on the EKC may hence also be ascribed to the absence of a comprehensive measure of emissions, which included all human activities, especially agriculture. A re-appraisal of the evidence on the emission-income relation with an appropriate methodology and emission measure appears highly desirable to inform both science and policy on future environmental degradation.

The methodological non-robustness of the evidence about the EKC hypothesis has been ascribed by Stern (2004) to four sources of econometric model mis-specification, namely: (i) heteroskedasticity, (ii) simultaneity, (iii) omitted variable bias and (iv) cointegration issues. These problems are phrased in terms of the most-commonly used approach in the estimation of emissions-income relations, which relies on a quadratic (or polynomial) regression of emissions on income. ${ }^{2}$

The present paper investigates the emissions-income relation taking a country-specific, timeseries approach, employing a cointegrated Vector AutoRegressive (VAR) model. This approach avoids the pitfalls of heterogeneity in the emissions-income relation across countries, which implies heteroskedasticity in a cross-sectional regression - see (i) above. The present analysis allows for both directions of causality between emissions and income, see (ii) above, and it allows for cointegration and a dynamic specification, see (iv) above.

Omitted variables have also been indicated as a source of econometric mis-specification, see (iii) above. However, if emissions and income are well described as integrated time series of order one, and they have a common trend, this property is also present when considering a group of three or more variables which includes the original emissions and income variables. In this sense common trends (i.e. cointegration) are 'robust' with respect to the omission of a third variable, thus addressing issue (iii) above. Hence the present approach appears to go a long way in avoiding several sources of model mis-specification indicated by Stern (2004).

Traditionally, the specification the EKC has taken the form of a regression equation in which (log) emissions per capita are specified to be a quadratic polynomial in (log) income per capita. Equivalently, the EKC specification assumes that the slope of the emissions-income relation is

\footnotetext{
${ }^{1}$ Many non monotonic forms of this relation have been considered in the EKC literature; the inverted U shape is a representative of this class.

${ }^{2}$ See also Wagner (2008) and Stern (2010) on critical issues in the standard econometric practise on the EKC.
} 
itself a polynomial function of income. Müller-Fürstenberger and Wagner (2007) and Wagner (2008) pointed out that the inclusion of the quadratic term in this time-series regression would give rise to incorrect (asymptotic) critical values, and this would imply incorrect inference on the regression coefficients. Hence, in this paper we omit the quadratic term in the polynomial regression, which is tantamount to approximating the slope of the emissions-income with a constant. This approximation is bound not to be critical in practice if the slope is varying not too rapidly as a function of income within the sample.

We consider three emission variables over the years 1970-2008 taken from the EDGARv4.2 database EC-JRC/PBL (2011), namely $\mathrm{CO}_{2}, \mathrm{SO}_{2}$ and a composite global warming index (denoted GWP100) in which all Kyoto-protocol greenhouse chemical compounds are converted to units of tonnes $\mathrm{CO}_{2}$-equivalent with the standard UNFCCC 100-year weighting factors. The comparison of results for these three chemical compounds allows to investigate how sensitive is the evidence on the EKC to the development of the energy-intensive sector in different countries.

The EDGAR-v4.2 database provides consistent global estimates for a range of emissions, and it covers the full IPCC emissions category set. The consistency of the data set is three-fold and concerns geographical coverage, accountancy of all sector-specific anthropogenic activities and the complete chemical composition of each emitting source under consideration, see Section 4 and the Appendix for more details. To the best of the authors' knowledge, this is the first paper to investigate the income-emissions relation using the GWP100 metric, which offers a more comprehensive indication of Greenhouse-Gas-led climate change.

The trends for these three emission series are expected to be possibly different. Previous studies have concentrated attention on $\mathrm{SO}_{2}$ because statistics on it were the most completely available; its inclusion in this study hence permits comparison with previous ones. Similarly to $\mathrm{SO}_{2}$, the series of $\mathrm{CO}_{2}$ is mostly driven by combustion-related anthropogenic activity; one would hence expect a certain similarity between the trends in $\mathrm{SO}_{2}$ and $\mathrm{CO}_{2}$. Unlike these two series, GWP100 contains many different anthropogenic activities including agriculture; the trends in GWP100 are hence expected to be possibly further away from the ones of $\mathrm{SO}_{2}$ and $\mathrm{CO}_{2}$.

At 5\% significance level, we find that for approximately two thirds of the cases, emissions and income are best described as difference stationary series without a common trend; for one quarter of the cases we find them to be difference stationary and cointegrated, and for approximately $5 \%$ of cases we find the series to be trend-stationary. These frequencies are consistent across different emission compounds, but are quite sensitive to the choice of the significance level. Moreover, different emissions for the same country do not necessarily show the same trending behavior, which let us conclude that the activity mix is not the determining factor in the EKC analysis.

In the case of cointegration, we find that the slope coefficient of income in the emissionincome relation is unrelated to the average level of national income. This is at odds with the prediction of the EKC hypothesis, under which the cross-section of slopes of countries' emissions should follow a polynomial in income. 
We test for causality and we find evidence of both directions of causality. For the case of unrelated stochastic trends, we find that more often emissions are found to cause income (through growth rates) than vice versa; this shows a predominance of the interpretation of the emissions-income relation as a production function rather than as a consumption function, see Coondoo and Dinda (2002). Again this is at odds with the implication of the EKC that increasing income, emissions tend to decrease.

The paper is organized as follows. Section 2 is devoted to a review of the literature on $\mathrm{EKC}$, and to more detailed comparison of the approach the present paper with it. Section 3 describes the econometric specification, while Section 4 describes the analyzed dataset. Section 5 describes the statistical analysis and reports results. Section 6 concludes.

\section{LiterATURE REVIEW}

The analysis of the emissions-income relation is complicated by a number of potential econometric problems, see Stern (2004). These include the 'spurious regression' problem, heterogeneity in the emissions-income relation across countries, and the existence of a dynamic specification, possibly involving both directions of causality. We illustrate these problems in turn, reporting both the relevant literature and the way the present paper approaches their solution.

Firstly, the presence of stochastic trends gives rise to the possibility of spurious regressions; Granger and Newbold (1974) and Phillips (1986) recognized this problem in modern econometrics and laid the foundation of its explanation. Nelson and Plosser (1982) found that many macroeconomic time series like income are well described as time series integrated of order 1 , denoted I(1). ${ }^{3}$ Stern and Kaufmann (1999) applied a similar analysis to environmental time series and they found that it is not unreasonable to assume that they are also I(1). This implies that the econometric tools required for the analysis of the emissions-income relation must allow for (possibly common) stochastic trends.

The same conclusion can be drawn from the analysis of Verbeke and De Clercq (2006), who simulated two unrelated random walks and recorded the frequency of spuriously significant regressions for the standard quadratic regression specification of EKC. They found that, for most of their parameter configurations, the quadratic regression indicated significant coefficients with probability 0.4, approximately the same frequency of countries for which Perman and Stern (2003) found support of the EKC on the basis of a quadratic regression. Their Monte Carlo experiment shows the importance of properly accounting for nonstationarity in the analysis of emissions-income relation. ${ }^{4}$ The approach taken in the present paper investigates the order of integration and cointegration of emissions and income, and hence stays clear of the pitfall of spurious regression.

The type of trend in income and emissions, and their interactions, greatly influences the long-term forecast of these variables. If the trends are stochastic (i.e. the cointegration rank

\footnotetext{
${ }^{3} \mathrm{I}(1)$ processes are often called 'stochastic trends'; one such process is the random walk, which contains Brownian motion in discrete time as a special case.

${ }^{4}$ Verbeke and De Clercq (2006) remarked that, "most empirical papers do not report whether the series are integrated or not. Basically this means that there is no way to tell if the reported results are due to the EKC or are spurious."
} 
is 0 or 1), effects of shocks to the system may be permanent. If, instead, the trends are only non-stochastic, i.e. deterministic (corresponding to a cointegration rank equal to 2), emissions and income are stationary around a linear trend and the long-term behavior of emissions only depends on the deterministic trend, which represent different factors from income. This would exclude any reduction in emissions due to an increase in income, as suggested by the EKC hypothesis. Hence the analysis of the cointegration rank is highly informative on the type of trends present in income and emissions, and on their long-run implications.

An issue related to the spurious regression problem is the treatment of the quadratic term. The literature on EKC posits that the shape of the emissions-income relation is similar to an inverted-U or $\mathrm{N}$ shape in levels, and it corresponds to the fact that the slope of the emissionsincome relation is a polynomial itself. In the case of an inverted-U relation, the slope is a downward-sloping line. We approximate the slope with a constant, in order to be able to use existing asymptotic results from the linear cointegration literature, see Johansen (1996). This approximation is bound not to be critical in practice if the slope is varying not too rapidly as a function of income within the sample. ${ }^{5}$

In this paper, after estimating the slopes of emissions-income relation, we consider the crosssection of estimates of emissions-income slopes as a function of countries income, and we find that the slopes coefficients do not align around any simple function of income, like a polynomial. This finding is at odds with the predictions of the EKC hypothesis.

A second difficulty encountered in the analysis of the emission-income relation is the one of cross-sectional heterogeneity. Countries in different stages of development and/or different degrees of trade openness possibly exhibit emission-income relations with different characteristics. This heterogeneity can be a source of error for instance in cross-country regression specifications that ignore it, and, albeit to a lesser extent, in panel data models, which require some degree of homogeneity. As pointed out by Müller-Fürstenberger and Wagner (2007) and Wagner (2008), this calls for less restricted panel data methods that do not require a high degree of homogeneity, or to country-specific time series models, like the ones employed here.

In this paper no homogeneity is assumed at the outset; every country is treated with a totally specific parametrization. This does not require parameters for different countries to be different but allows them to be so. With this strategy we can discuss how similar parameter estimates are ex-post. In this respect, therefore, the present analysis can be considered as a check of homogeneity. Our results show a high degree of heterogeneity.

One could doubt that this heterogeneity could be the result of a lack of uniformity in the data-construction. In order to discard this as a possible explanation, we analyze the EDGARv4.2 dataset, which is highly scrutinized in order to maintain a consistent, technology-based, bottom-up inventory of emissions across all countries, all anthropogenic sectors and all chemical substances, see Janssens-Maenhout et al. (2011). The high degree of heterogeneity in the results cannot hence be ascribed to the quality of the data.

\footnotetext{
${ }^{5}$ Several investigators, see Stern $(2004,2010)$, have favored a monotonic emissions-income relation instead of a non-monotonic one. Several studies, see the list of references on page 2181 in Stern (2010), do not find support for a non-monotonic emissions-income relation as predicted by the EKC hypothesis.
} 
The third difficulty in the analysis of the emissions-income relation is the fact that such a relation may well be a dynamic one, and not a static one as is traditionally assumed by the EKC hypothesis. The dynamics of the responses of emissions and income may or may not involve feedback from emissions to income and vice-versa. This opens up the question of the direction of Granger-causality between emissions and income, which helps to distinguish between the competing interpretations of the emissions-income relation as a production and/or a consumption function, see e.g. Siebert (2008).

In fact, the causality from income to emissions is a characteristic of the interpretation of the emissions-income relation as a consumption function, where emissions are a bad item from the point of view of consumer preferences. The causality from emissions to income is instead a characteristic of the emissions-income relation as a production function, where emissions are an input in the production function. Assessing the direction of causality is hence a way to investigate the prevalent economic characteristic of the income-emissions nexus and to predict the effects of a change in income or in emissions on the other variable. Coondoo and Dinda (2002) have analysed causality between income and $\mathrm{CO}_{2}$ using panel data models on the levels of the variables.

In this paper we extend the analysis of causality allowing income and emissions to be integrated and possibly cointegrated. This implies that one may have causality in growth rates alone, or causality through the growth rates as well as through the equilibrium correction mechanism. Finally, if the variables are found to be trend-stationary, we analyse causality in levels.

The present cointegrated VAR models hence provide a unified framework to address the issues of nonstationarity, heterogeneity and the dynamic nature of the emissions-income relation, where causality can be investigated according to the type of model selected by the data. The cointegrated VAR approach has recently received increasing attention in the literature on the emissions-income relation: Ang (2007) analyses $\mathrm{CO}_{2}$ emissions and income for France; Baek et al. (2009) analyze $\mathrm{SO}_{2}$, income and trade using data for 50 countries; Coondoo and Dinda (2008) analyse $\mathrm{CO}_{2}$ emissions, income and inequality measures for data aggregated over continents. The present paper takes the same approach, applying it also to GWP100 and $\mathrm{CO}_{2}$, and considers more than 150 countries.

\section{ECONOMETRIC SPECIFICATION}

Consider the following standard reduced-form specification of the emissions-income relation

$$
e_{t}=\beta_{0}+\beta_{1} y_{t}+u_{t}
$$

where $e_{t}$ is $\log$ of emissions per capita and $y_{t}$ is log of per capita income and $u_{t}$ is some stationary error. This specification is used e.g. in Tamazian and Rao (2010) with additional regressors measuring inflation, foreign direct investment, price liberalization and trade openness. Because we wish to investigate the presence of common trends in emissions and income without controlling for extra factors, we omit the remaining variables.

Eq. (1) implies that, if $e_{t}$ and $y_{t}$ are trending, they have a common trend, because $u_{t}$ is stationary. In particular when $e_{t}$ and $y_{t}$ are integrated of order $1, \mathrm{I}(1)$, then eq. (1) is a cointegrating relation in the sense of Engle and Granger (1987). This implies that the 
commonality of trends in emissions and income corresponds to the presence of a cointegrating relation. Tests on the cointegrating rank are hence tests of the presence of a common trend of the form in eq. (1).

The economic rationale for an income-emission relation is well summarized in Stern (2004) and Müller-Fürstenberger and Wagner (2007). The implied reduced-form emissions-income relation is usually taken to be of the following form

$$
e_{t}=\beta_{0}+\beta_{1} y_{t}+\beta_{2} y_{t}^{2}+u_{t}
$$

which differs from eq. (1) by the inclusion of the quadratic term $\beta_{2} y_{t}^{2}$. An equivalent way to obtain the quadratic specification is by allowing the slope coefficient $\beta_{1}$ in eq. (1) to be a function of $y_{t}$. In fact, replacing the slope coefficient $\beta_{1}$ in eq. (1) with a polynomial in $y_{t}$, like $\gamma_{0}+\gamma_{1} y_{t}$ or, more in general, with $\sum_{j=0}^{d} \gamma_{j} y_{t}^{j}$, one obtains a polynomial specification of $e_{t}$ as a function of $y_{t}$ (of order $d+1$ ). When $d=1$ one finds eq. (2) with $\beta_{1}=\gamma_{0}, \beta_{2}=\gamma_{1}$, while $d=0$ corresponds to the original linear specification in eq. (1).

Müller-Fürstenberger and Wagner (2007) and Wagner (2008) pointed out that including the quadratic regressor $y_{t}^{2}$ in eq. (2) when $y_{t}$ is an $\mathrm{I}(1)$ process invalidates both the asymptotic normality for stationary regressions and the limit distribution results derived for the linear cointegration case. In order to avoid this pitfall, in this paper we decided to omit the quadratic term in (2) and retain the linear specification in eq. (1) only. The (possible) associated approximation of the slope with a constant is bound not to be critical in practice if $\sum_{j=0}^{d} \gamma_{j} y_{t}^{j}$ is varying not too rapidly with $y_{t}$.

In order to account for both stochastic and deterministic linear trends we assume that $e_{t}$ and $y_{t}$ are generated (or well-described) by a vector autoregressive process (VAR) of the following form

$$
\left(\begin{array}{l}
e_{t} \\
y_{t}
\end{array}\right)=\mu_{0}+\mu_{1} t+\sum_{j=1}^{k} A_{j}\left(\begin{array}{c}
e_{t-j} \\
y_{t-j}
\end{array}\right)+\varepsilon_{t} .
$$

Here $\varepsilon_{t}$ are independent and identically $N(0, \Omega)$-distributed $n \times 1$ vectors, $A_{j}$ and $\Omega$ are $n \times n$ matrices and $\mu_{0}$ and $\mu_{1}$ are $n \times 1$ vectors of parameters, where $n=2$. In the following we write eq. (3) concisely as $A(L) x_{t}=\mu_{0}+\mu_{1} t+\varepsilon_{t}$ with $x_{t}:=\left(e_{t}, y_{t}\right)^{\prime}$ (a column vector), where $A(L):=I_{n}-A_{1} L-\ldots-A_{k} L^{k}$ is the AR polynomial in the lag operator $L, L x_{t}:=x_{t-1}$. In the following let also $\Delta:=1-L$ indicate the first difference operator, $\Delta x_{t}:=x_{t}-x_{t-1}$.

Different AR polynomials give rise to stationary (mean-reverting) or nonstationary (trending) $x_{t}$ processes. In particular, a subclass of eq. (3) generates $\mathrm{I}(1)$ processes, which possess a trending behavior. I(1) processes are hence called 'stochastic trends'. If $x_{t}$ is $\mathrm{I}(1)$ one has 'cointegration' when there exist $r$ linearly independent linear combinations of $x_{t}$, collected as columns in the matrix $\beta$, such that $\beta^{\prime} x_{t}$ is a stationary process; in this case $r$ is called the 'cointegration rank'. Granger's Representation Theorem, see Johansen (1996), Theorem 4.2, states that the cointegration rank $r$ and the number of (common) stochastic trends $n-r$ are complementary, i.e. their sum gives the number of variables $n$, where $n=2$ in the present case.

Here we label the case $0<r<n$ (which for $n=2$ just consists of $r=1$ ) as the cointegrated case. In the case $r=0$, there are 2 unrelated I(1) trends; we call this the 'unrelated random 
walks' case. Finally when $r=2$, there are no I(1) trends and the process $x_{t}$ is stationary around the deterministic trend $\mu_{0}+\mu_{1} t$ provided $\mu_{1} \neq 0$; this case is called the 'trend-stationary' case.

Remark that the three cases of $r=0$ (unrelated random walks), $r=1$ (cointegration) and $r=2$ (trend-stationary case) imply very different behaviors for the trends governing emissions and income. In the unrelated random walks case, the two variables are driven by two unrelated stochastic trends. This is contrary to the prediction of the EKC hypothesis. In the cointegrated case, there is a single common stochastic trend; this is in line with (1). Finally, in the trendstationary case, emissions and income may influence each other only in the short run, and their long-run movements are dictated by the slope of the linear trends. Also this case is contrary to the prediction of the EKC hypothesis. Hence the only case which accords with the EKC hypothesis is the cointegrated case, and discriminating among these possibilities (i.e. choosing the cointegration rank) is of high interest for the EKC debate.

\section{DATA}

We consider emissions per capita covering GWP100, $\mathrm{SO}_{2}$, and $\mathrm{CO}_{2}$ taken from the EDGARv4.2 database EC-JRC/PBL (2011). The EDGAR-v4.2 database provides consistent global estimates for a range of emissions, and it covers the full IPCC emissions category set. The consistency of the data set is three-fold and concerns the following aspects:

(1) geographical coverage: all world countries are taken into account with the same methodology using standard IPCC (2006) emission factors to the extent possible;

(2) sector-specific activities: energy-related as well as agriculture-related activities are for all countries taken into account with the same sector-specific definitions. Agriculturerelated activities become important when considering all GHGs with the GWP100 metric, as they contributed $12 \%$ of the total in 2008. (In the case of $\mathrm{CO}_{2}$, agricultural activities contributed only $0.4 \%$ to net total global emissions, as short cycle carbon emissions from biomass and agricultural waste burning were not included, in accordance with UNFCCC emissions inventorying procedures);

(3) chemical substances: the emissions of multiple GHG and air pollutants by a single human activity are modelled with multipollutant single sources in EDGAR-v4.2.

The emissions of the three chemical compounds have a different activity composition, as detailed in the Appendix, to which we refer for more details. GDP data is taken from Penn World Table (PWT 7.0), see Heston et al. (2011). Population data is taken from UNSTAT.

To facilitate comparison with Baek et al. (2009), henceforth referred to as Baek, we report complete results for the 50 countries considered in their paper. We subdivide these 50 countries into two groups: BI, which are Annex I countries, and BnI, which includes non-Annex I countries. The BI group consists of 23 countries, the BnI is made of 27 countries. The remaining countries are referred to as the Rest of the World group (RoW); for the RoW group we report more aggregated results. Emissions and/or GDP data were missing or incomplete for some countries, which resulted in 153, 149, 151 valid complete datasets for GWP100, $\mathrm{SO}_{2}$ and $\mathrm{CO}_{2}$ respectively. For brevity, in the following tables and figures GWP100 is abbreviated to GWP. 

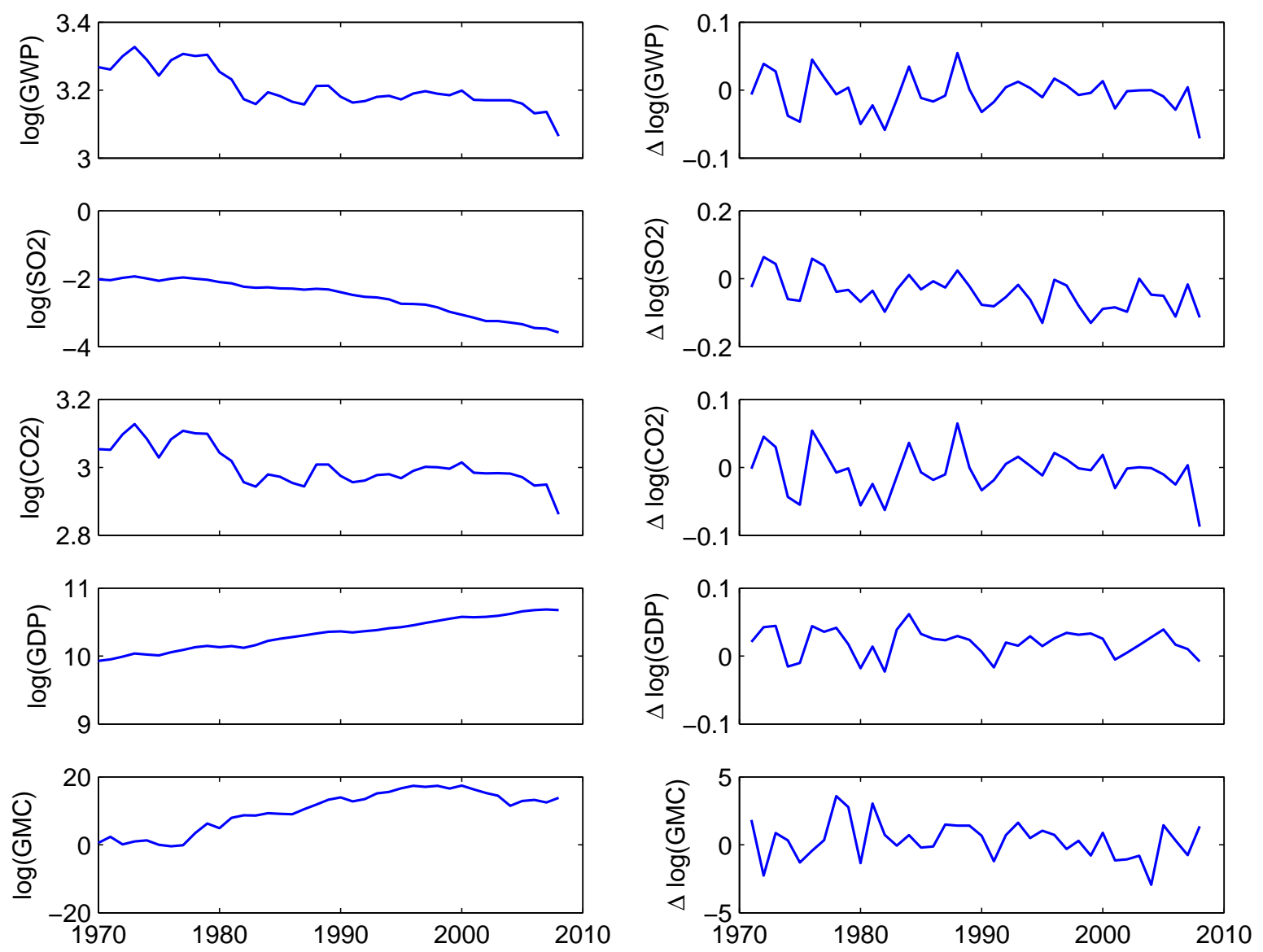

Figure 1. Time series of US GWP, $\mathrm{SO}_{2}, \mathrm{CO}_{2}$, GDP, in log-levels, 1970-2008. The last time series GMC is a simulation of a random walk (discretized Brownian motion).

Sample graphs of the data are reported in Fig. 1 and Fig. 2, where we consider the case of the US for illustration. Fig. 1 reports the time-series plots of US emissions and income percapita, in log-levels (left panel) and first difference (right panel). One observes that log-levels are trending, while the first differences appear stationary (mean-reverting). For comparison we also report a simulated random walk, denoted as log GMC, shorthand for Gas Monte Carlo. From these observations one infers that emissions and income are both trending variables, with a trend that is not dissimilar from a stochastic trend generated by $\mathrm{I}(1)$ process.

Fig. 2 reports cross-plots of emissions versus income in the US, 1970-2008. These graphs are reminiscent of stages along the inverted U relationship predicted by the EKC hypothesis. However, these relations may well be spurious, as it is argued in Verbeke and De Clercq (2006). This possibility is demonstrated by the lower-right panel of Fig. 2, which reports the cross plot of the simulated random walk GMC versus the log of US GDP. Eye-inspection of this graph would indeed conform to the inverted-U relationship narrative of the EKC, where instead the two series are stochastically independent; this relation is hence spurious. Therefore, the apparent emission-income relation in cross plots of emissions versus income in levels may well be the artifact of the presence of (possibly unrelated) trending variables. We next turn to the results of the econometric analysis. 

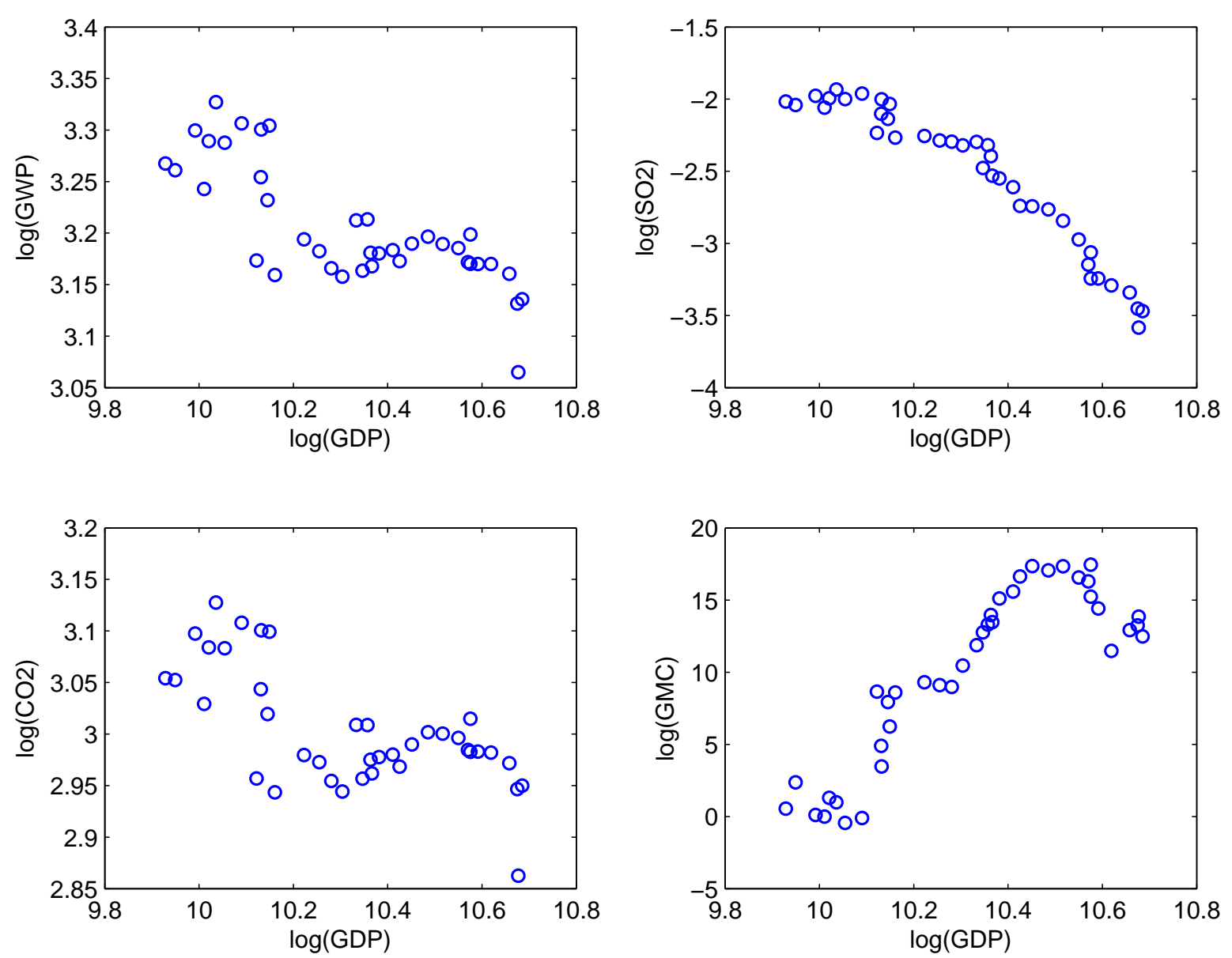

Figure 2. Cross plot of the logarithms of US GWP, $\mathrm{SO}_{2}, \mathrm{CO}_{2}$ versus the logarithm of GDP, 1970-2008. The bottom right panel reports the cross plot of a simulated random walk (log GMC) versus the logarithm of US GDP reported in Fig. 1.

\section{EMPIRICAL RESULTS}

This section describes the econometric analysis and results. We concentrate attention on the following aspects: the selection of the VAR lag length $k$, the (co)integration analysis and tests of the various forms of Granger-causality. These aspects are treated in turn in the next subsections.

5.1. Choice of lag length. The statistical analysis of the VAR model starts with the choice of lag length $k$ in (3). Following standard practice, we relied on Schwarz's criterion for the choice of lag length; this selection criterion selects the correct $k$ with probability 1 as the sample size increases not only for $\mathrm{I}(0)$ processes but also for $\mathrm{I}(1)$ processes with cointegrated variables and for trend-stationary processes, see (Luetkepohl and Kratzig, 2004, Chapter 3) and reference therein. We varied $k$ among the values 2, 3 and 4, and we chose the model which minimized Schwarz's criterion. We excluded the value $k=1$ because the dynamics of the system would be overly restricted. ${ }^{6}$

\footnotetext{
${ }^{6}$ In fact when $k=1$, the test of $r=0$ is really a test that $\Delta x_{t}$ is a white-noise process with no dynamics.
} 


\begin{tabular}{lllllll}
\hline lag length & \multicolumn{3}{l}{ Rest of the World } & \multicolumn{4}{c}{ All countries } \\
\hline emissions & GWP & $\mathrm{SO}_{2}$ & $\mathrm{CO}_{2}$ & $\mathrm{GWP}$ & $\mathrm{SO}_{2}$ & $\mathrm{CO}_{2}$ \\
\hline$k=2$ & 97 & 90 & 96 & 145 & 139 & 144 \\
$k=3$ & 6 & 8 & 3 & 8 & 9 & 4 \\
$k=4$ & 0 & 1 & 2 & 0 & 1 & 3 \\
\hline missing values & 99 & 103 & 101 & & & \\
\hline
\end{tabular}

TABle 1. Counts of countries with selection of lag-lengths $k$ in (3) based on Schwarz's criterion. Rest of the World refers to countries non included in Baek, and it includes both Annex I and non-Annex I countries. Missing values are due to countries with incomplete datasets.

For the BI group, $k=2$ was the selected lag length for all country-chemical compound combinations. The same applied to the selected BnI group, except for the following cases, where $k=3$ was selected: Brasil - $\mathrm{CO}_{2}$, El Salvador - GWP and $\mathrm{SO}_{2}$, Peru - GWP. Results are reported in Table 1 for the remaining countries, along with total counts. The overall percentage of selected lag-length $k$ equal to 2 is above $93 \%$ for all chemical compounds; in the remaining cases $k=3$ and 4 were selected. This shows that there is (an albeit small) heterogeneity in lag-lengths across countries and chemical compounds.

In their study, Baek et al. (2009) chose $k=2$ for 19 countries and $k=1$ for the remaining 31 countries. We selected comparably higher values of $k$; this accords with the suggestion by Gonzalo (1994) based on the observation that the "cost of overparametrizing by including more lags in the ECM [i.e. in the VAR] is small in terms of efficiency lost [...] This is not the case if the ECM is underparametrized" (page 220). ${ }^{7}$

5.2. Cointegration rank. In this subsection we estimate the cointegration rank $r$, which is the rank of the matrix $\Pi:=-A(1)$. Johansen (1996) Chapter 12 describes a procedure for the estimation of the cointegration rank $r$ based on a sequence of likelihood ratio (LR) tests, which we summarize here. The LR tests are based on the maximized likelihood for models of the form in eq. (3) under the restriction

$$
H(j): r \leq j
$$

The LR test that compares models $H(j)$ and $H(n)$ is called the 'trace test' and it is indicated as $L R(j \mid n)$; its limiting distribution has been derived and tabulated, see Johansen (1996) Table 15.4 .

For the present case $n=2$ the sequence of LR tests is just $L R(0 \mid 2)$ and $L R(1 \mid 2)$; if $L R(0 \mid 2)$ does not reject, one selects $r$ equal to 0 ; otherwise one considers the next test $L R(1 \mid 2)$. If $L R(1 \mid 2)$ does not reject, one selects $r$ equal to 1 , otherwise one selects $r$ equal to 2 . This procedure selects the correct rank $r$ with probability at least equal to $1-\gamma$ in large samples, where $\gamma$ is the significance level used in the tests $L R(0 \mid 2)$ and $L R(1 \mid 2)$, see Johansen (1996).

\footnotetext{
${ }^{7}$ See the following subsection 5.3 for a definition of the ECM.
} 
In order to measure the sensitivity of the selection of the cointegration rank with respect to $\gamma$, we computed the tests $L R(0 \mid 2)$ and $L R(1 \mid 2)$, and we approximated their $p$-values using the technique proposed in Boswijk and Doornik (2005). ${ }^{8}$ The selected cointegration ranks for significance levels $\gamma=0.10,0.05,0.01$ are reported in Tables 2, 3, 4 .

It can be seen that for the majority of countries $r$ is selected equal to 0 . This percentage varies with the significance level and chemical compound; overall the frequency of $r=0$ for GWP, $\mathrm{SO}_{2}, \mathrm{CO}_{2}$, are of $69 \%, 68 \%$, and $71 \%$ respectively at significance level $\gamma=0.05$; the frequency of $r=1$ is instead of $26 \%, 26 \%$, and $27 \%$ respectively.

When varying $\gamma$ across $0.1,0.05,0.01$, one finds that for GWP the frequency of $r=0$ goes from $56 \%$ to $84 \%$; similar variations are found for $\mathrm{SO}_{2}$ and $\mathrm{CO}_{2}$. Ranges of a similar amplitude are also found for the choices $r=1$ and $r=2$. Hence the variation in the selected cointegration ranks with respect to $\gamma$ is substantial. While this aspect requires care in the interpretation of the results, one needs to fix the significance level for subsequence analysis; we fixed it at $\gamma=0.05$.

The frequency of $r=0$ varies also with country group, especially for GWP. At $\gamma=0.05$ for GWP, $\mathrm{SO}_{2}, \mathrm{CO}_{2}$ it goes from $65 \%, 52 \%, 65 \%$ for the BI group to $78 \%, 74 \%, 74 \%$ for the $\mathrm{BnI}$ group. One can observe a relatively higher frequency of no cointegration in the BnI group for the GWP series, which contains more diverse anthropogenic activities. Thus one finds significant variation also across country groups.

The estimated cointegration rank is not always the same for different chemical compounds of each single country. For the US, for instance, $r$ is selected equal to 1 for GWP and $\mathrm{CO}_{2}$ and it is estimated equal to 2 for $\mathrm{SO}_{2}$ at significance level 0.05. This signals that for some chemical compounds one may have a level relationship, while for others there may not exist a level relation. ${ }^{9}$ On a global scale, the hypothesis of a level relation between emissions and income is in the majority of cases at odds with the data.

Remark that $r=0$ is selected more often for GWP than for $\mathrm{CO}_{2}$ and $\mathrm{SO}_{2}$. For the selected 50 countries in the $\mathrm{BI}$ and $\mathrm{BnI}$ groups, it can be seen that when no cointegration is found for $\mathrm{CO}_{2}$ and for $\mathrm{SO}_{2}$, this also applies for GWP. This may be due to the presence of many different anthropogenic activities including agriculture in GWP, for which the hypothesis of a single and stable production technology over the sample period may be harder to meet than for $\mathrm{CO}_{2}$ and $\mathrm{SO}_{2}$.

Finally, for approximately $5 \%$ of cases the variables are found to be trend-stationary, i.e. $r$ is selected equal to 2. In these cases, there is no influence of income on emissions in the long run, whose path is governed by the linear trend.

\footnotetext{
${ }^{8}$ The approximation based on the gamma distribution proposed by Boswijk and Doornik (2005) was used for the limit distribution of $L R(j \mid n)$. The number of steps in the random walks that approximate the Brownian motions was set equal to the effective sample size; this corresponds to applying the factor $a$ in Bartlett's correction formula (4) in Johansen (2002), which is the part of the correction that does not depend on estimated parameters.

${ }^{9}$ Given that the GDP series for the US is common to the system with GWP and $\mathrm{SO}_{2}$, the selected ranks of 1 and 2 are not consistent, because GDP either contains an I(1) component or not. This is a limitation of the inferential procedure. In the following we do not try to resolve these conflicts, but proceed in the analysis taking the selected cointegration rank as given.
} 


\begin{tabular}{llll|lll|llll}
\hline & \multicolumn{3}{c|}{$\mathrm{GWP}$} & \multicolumn{3}{|c|}{$\mathrm{SO}_{2}$} & \multicolumn{3}{c}{$\mathrm{CO}_{2}$} \\
significance level & 0.10 & 0.05 & 0.01 & 0.10 & 0.05 & 0.01 & 0.10 & 0.05 & 0.01 \\
\hline Australia & 0 & 0 & 0 & 1 & 0 & 0 & 0 & 0 & 0 \\
Austria & 1 & 1 & 1 & 1 & 1 & 0 & 1 & 1 & 1 \\
Belgium & 1 & 0 & 0 & 2 & 2 & 1 & 0 & 0 & 0 \\
Canada & 0 & 0 & 0 & 1 & 0 & 0 & 0 & 0 & 0 \\
Denmark & 0 & 0 & 0 & 0 & 0 & 0 & 0 & 0 & 0 \\
Finland & 1 & 1 & 0 & 2 & 2 & 1 & 1 & 1 & 0 \\
France & 0 & 0 & 0 & 0 & 0 & 0 & 0 & 0 & 0 \\
Greece & 2 & 2 & 1 & 1 & 1 & 1 & 2 & 2 & 1 \\
Iceland & 0 & 0 & 0 & 0 & 0 & 0 & 0 & 0 & 0 \\
Ireland & 1 & 1 & 1 & 0 & 0 & 0 & 1 & 1 & 0 \\
Italy & 1 & 0 & 0 & 0 & 0 & 0 & 1 & 0 & 0 \\
Japan & 0 & 0 & 0 & 0 & 0 & 0 & 0 & 0 & 0 \\
Luxembourg & 0 & 0 & 0 & 0 & 0 & 0 & 0 & 0 & 0 \\
Netherlands & 0 & 0 & 0 & 1 & 1 & 0 & 0 & 0 & 0 \\
New Zealand & 0 & 0 & 0 & 1 & 1 & 0 & 0 & 0 & 0 \\
Norway & 0 & 0 & 0 & 1 & 0 & 0 & 0 & 0 & 0 \\
Portugal & 1 & 1 & 1 & 2 & 1 & 1 & 1 & 1 & 1 \\
Spain & 2 & 1 & 1 & 2 & 2 & 2 & 2 & 2 & 1 \\
Sweden & 0 & 0 & 0 & 0 & 0 & 0 & 0 & 0 & 0 \\
Switzerland & 0 & 0 & 0 & 2 & 2 & 0 & 2 & 1 & 1 \\
Turkey & 2 & 1 & 1 & 2 & 1 & 0 & 1 & 0 & 0 \\
United Kingdom & 0 & 0 & 0 & 0 & 0 & 0 & 1 & 0 & 0 \\
United States & 1 & 1 & 0 & 2 & 2 & 1 & 1 & 1 & 0 \\
\hline & & & & & & & & & \\
\hline
\end{tabular}

TABLE 2. Selected cointegration rank $r$, at significance levels $0.10,0.05,0.01$. Annex I countries in Baek. The cointegration rank $r$ for the two variables, emissions and income, can be interpreted as follows: $r=0$ means that there are two unrelated random walks (with drift); $r=1$ means that there is single random walk with drift, $r=2$ implies that emissions and income are stationary around two linear trends (with possibly different slopes). In the cases $r=0$ or $r=1$ there are long-term effects of shocks to the variables, in case $r=2$ there are no long-term effects of shocks.

5.3. Level relations. In this subsection we present estimates of the cointegrating relations between emissions and income when the system is found to be cointegrated, i.e. when the selected $r$ equals 1 . When the VAR is $\mathrm{I}(1)$ and $r<p$, it can be rewritten in the form of the following error correction model (ECM), see Davidson et al. (1978),

$$
\Delta x_{t}=\alpha\left(\beta^{\prime}, \beta_{D}\right)\left(\begin{array}{c}
x_{t-1} \\
t
\end{array}\right)+\sum_{i=1}^{k-1} \Gamma_{i} \Delta x_{t-i}+\mu_{0}+\varepsilon_{t},
$$




\begin{tabular}{|c|c|c|c|c|c|c|c|c|c|}
\hline \multirow[b]{2}{*}{ significance level } & \multicolumn{3}{|c|}{ GWP } & \multicolumn{3}{|c|}{$\mathrm{SO}_{2}$} & \multicolumn{3}{|c|}{$\mathrm{CO}_{2}$} \\
\hline & 0.10 & 0.05 & 0.01 & 0.10 & 0.05 & 0.01 & 0.10 & 0.05 & 0.01 \\
\hline Argentina & 0 & 0 & 0 & 0 & 0 & 0 & 0 & 0 & 0 \\
\hline Bolivia & 0 & 0 & 0 & 0 & 0 & 0 & 0 & 0 & 0 \\
\hline Brazil & 0 & 0 & 0 & 1 & 1 & 0 & 0 & 0 & 0 \\
\hline Chile & 1 & 1 & 0 & 2 & 0 & 0 & 1 & 1 & 0 \\
\hline China & 0 & 0 & 0 & 0 & 0 & 0 & 0 & 0 & 0 \\
\hline Colombia & 0 & 0 & 0 & 0 & 0 & 0 & 0 & 0 & 0 \\
\hline Costa Rica & 0 & 0 & 0 & 0 & 0 & 0 & 0 & 0 & 0 \\
\hline Ecuador & 1 & 1 & 1 & 1 & 1 & 0 & 1 & 1 & 1 \\
\hline El Salvador & 1 & 0 & 0 & 1 & 1 & 0 & 0 & 0 & 0 \\
\hline Guatemala & 0 & 0 & 0 & 0 & 0 & 0 & 1 & 1 & 0 \\
\hline Honduras & 0 & 0 & 0 & 0 & 0 & 0 & 0 & 0 & 0 \\
\hline India & 0 & 0 & 0 & 0 & 0 & 0 & 0 & 0 & 0 \\
\hline Indonesia & 0 & 0 & 0 & 0 & 0 & 0 & 0 & 0 & 0 \\
\hline Israel & 0 & 0 & 0 & 0 & 0 & 0 & 0 & 0 & 0 \\
\hline Jordan & 1 & 1 & 1 & 1 & 1 & 0 & 1 & 1 & 1 \\
\hline Korea, Republic of & 0 & 0 & 0 & 1 & 1 & 0 & 1 & 0 & 0 \\
\hline Mexico & 0 & 0 & 0 & 1 & 1 & 1 & 1 & 1 & 0 \\
\hline Nicaragua & 0 & 0 & 0 & 0 & 0 & 0 & 1 & 1 & 1 \\
\hline Panama & 0 & 0 & 0 & 0 & 0 & 0 & 0 & 0 & 0 \\
\hline Paraguay & 0 & 0 & 0 & 0 & 0 & 0 & 0 & 0 & 0 \\
\hline Peru & 1 & 0 & 0 & 0 & 0 & 0 & 0 & 0 & 0 \\
\hline Philippines & 0 & 0 & 0 & 0 & 0 & 0 & 0 & 0 & 0 \\
\hline Singapore & 1 & 1 & 0 & 1 & 0 & 0 & 1 & 1 & 1 \\
\hline Sri Lanka & 0 & 0 & 0 & 0 & 0 & 0 & 0 & 0 & 0 \\
\hline Thailand & 1 & 1 & 0 & 1 & 0 & 0 & 0 & 0 & 0 \\
\hline Uruguay & 2 & 1 & 0 & 2 & 1 & 0 & 1 & 0 & 0 \\
\hline Venezuela & 0 & 0 & 0 & 0 & 0 & 0 & 0 & 0 & 0 \\
\hline
\end{tabular}

TABLE 3. Selected cointegration rank $r$, at significance levels 0.10, 0.05, 0.01. non-Annex I countries in Baek. See caption of Table 2 for the interpretation of the cointegration rank $r$.

where $\alpha$ and $\beta$ are $n \times r$ matrices of full column rank $r$; this result is again part of Granger's Representation Theorem. In case $r=1$, there is only one cointegrating linear combination, of the form

$$
\operatorname{ecm}_{t}:=\left(\beta^{\prime}, \beta_{D}\right)\left(x_{t-1}^{\prime}: t\right)^{\prime}=\beta_{1} x_{1 t-1}+\beta_{2} x_{2 t-1}+\beta_{D} t
$$

where $\mathrm{ecm}_{t}$ is stationary. The cointegrating linear combination describes a level relation (or equilibrium relation). The linear combination $\beta_{1} x_{1 t-1}+\beta_{2} x_{2 t-1}$ is stationary around the linear trend $-\beta_{D} t$. 


\begin{tabular}{|c|c|c|c|c|c|c|c|c|c|}
\hline significance level & 0.10 & 0.05 & 0.01 & 0.10 & 0.05 & 0.01 & 0.10 & 0.05 & 0.01 \\
\hline emissions & \multicolumn{3}{|c|}{ GWP } & \multicolumn{3}{|c|}{$\mathrm{SO}_{2}$} & \multicolumn{3}{|c|}{$\mathrm{CO}_{2}$} \\
\hline missing values & \multicolumn{3}{|c|}{99} & \multicolumn{3}{|c|}{103} & \multicolumn{3}{|c|}{101} \\
\hline \multicolumn{10}{|c|}{ Annex I countries in Baek } \\
\hline$r=0$ & 13 & 15 & 17 & 9 & 12 & 17 & 12 & 15 & 18 \\
\hline$r=1$ & 7 & 7 & 6 & 7 & 6 & 5 & 8 & 6 & 5 \\
\hline$r=2$ & 3 & 1 & 0 & 7 & 5 & 1 & 3 & 2 & 0 \\
\hline \multicolumn{10}{|c|}{ non-Annex I countries in Baek } \\
\hline$r=0$ & 19 & 21 & 25 & 17 & 20 & 26 & 18 & 20 & 23 \\
\hline$r=1$ & 7 & 6 & 2 & 8 & 7 & 1 & 9 & 7 & 4 \\
\hline$r=2$ & 1 & 0 & 0 & 2 & 0 & 0 & 0 & 0 & 0 \\
\hline \multicolumn{10}{|c|}{ Rest of the World } \\
\hline$r=0$ & 54 & 69 & 87 & 58 & 70 & 86 & 62 & 72 & 91 \\
\hline$r=1$ & 39 & 27 & 13 & 36 & 25 & 11 & 30 & 28 & 9 \\
\hline$r=2$ & 10 & 7 & 3 & 5 & 4 & 2 & 9 & 1 & 1 \\
\hline \multicolumn{10}{|c|}{ All countries } \\
\hline$r=0$ & 86 & 105 & 129 & 84 & 102 & 129 & 92 & 107 & 132 \\
\hline$r=1$ & 53 & 40 & 21 & 51 & 38 & 17 & 47 & 41 & 18 \\
\hline$r=2$ & 14 & 8 & 3 & 14 & 9 & 3 & 12 & 3 & 1 \\
\hline
\end{tabular}

TABLE 4. Counts of countries by selected cointegration rank $r$, at significance levels $0.10,0.05,0.01$. See caption of Table 2 for the interpretation of the cointegration rank $r$.

We are interested in the statistical significance of the coefficients $\beta_{1}$ and $\beta_{2}$, i.e. in the hypothesis

$$
H_{0 i}^{\beta}: \beta_{i}=0 .
$$

This hypothesis is a special case of the test $\beta=H \varphi$ where $H$ is a known $n \times s$ matrix; the likelihood ratio test for this hypothesis are discussed in Johansen (1996) Chapter 7.2, who showed that it has a standard $\chi^{2}$ limit distribution with $r(n-s)$ degrees of freedom; in the present case $r(n-s)=1$. Note that, for consistency with the choice of cointegrating rank, one cannot have both $\beta_{1}=0$ and $\beta_{2}=0$.

Remark that if hypothesis (6) is not rejected for $i=2$, say, it means that $x_{1 t}$ is stationary around a linear trend with slope $-\beta_{D} / \beta_{1}$. If, on the other hand, the hypothesis in eq. (5) is rejected for $i=1$, say (i.e. $\beta_{1} \neq 0$ ), then eq. (5) can be normalized for identification by setting $\beta_{1}=-1$, implying that $x_{1 t-1}=\beta_{2} x_{2 t-1}+\beta_{D} t-\mathrm{ecm}_{t}$. After this normalization, one could interpret $\beta_{2}$ as the long-run slope of the level relation between $x_{1 t}$ and $x_{2 t}$. The EKC hypothesis prescribes that $\beta_{2}$ depends on the average level of income of the country, with at least one change of sign for increasing income level. ${ }^{10}$

\footnotetext{
${ }^{10}$ As noted in Luetkepohl (2005) and in Baek et al. (2009), $\beta_{2}$ is not an elasticity due to the presence of dynamics in the system, see Johansen (2005) for an interpretation of identified cointegrating coefficients in terms
} 

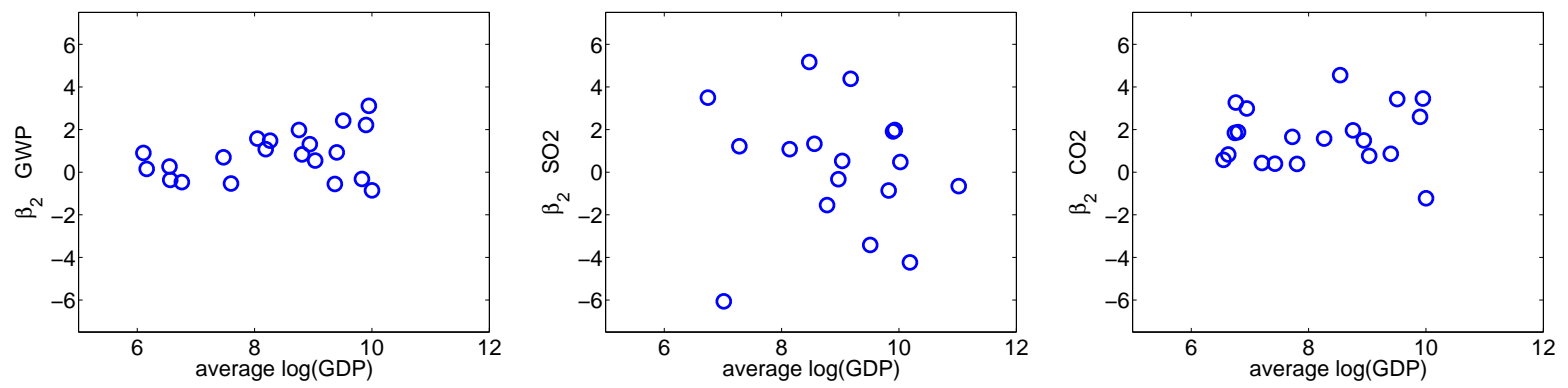

Figure 3. Estimates of $\beta_{2}$ for selected cointegration rank $r$ equal to 1 plotted versus average $\log$ GDP. The cases of $\beta_{2}=0$ or $\beta_{2}=-1$ are not included. Left panel: GWP; central panel: $\mathrm{SO}_{2}$; right panel: $\mathrm{CO}_{2}$.

The estimates of $\beta_{2}$ were obtained after testing for their significance using hypothesis (6). More precisely, we first tested hypothesis (6) on single coefficients for $i=1,2, D$. We next retained all variables for which (6) was rejected, and tested that the remaining coefficients were all simultaneously equal to zero. ${ }^{11}$

Also this second test is a special case of the hypothesis $\beta=H \varphi$, and inference is asymptotically $\chi^{2}$. If the joint hypothesis was not rejected, we estimated $\beta$ under this restriction; otherwise we relaxed the 0 restriction on the variable which yielded the highest $p$-value in the single variable test, and repeated the procedure until the joint test of the excluded coefficients was insignificant.

Overall, the vector $\beta=(-1,0,0)^{\prime}$ (which implies stationarity of emissions) was selected only for the following chemical compound-country pairs; GWP: Bahrain, Chad, Tonga; $\mathrm{SO}_{2}$ : Albania, Cambodia, Comoros, Ecuador, Mexico, Morocco, Nigeria, Saint Kitts and Nevis, Turkey, Uganda; $\mathrm{CO}_{2}$ : Brunei D., Cambodia, Mexico. The vector $\beta=(0,-1,0)^{\prime}$ implying that income is stationary was selected only for Malta $\mathrm{CO}_{2}$.

Fig. 3 reports the estimates of $\beta_{2}$ plotted against the sample average country log GDP per capita; the cases of $\beta_{2}=0$ or $\beta_{2}=-1$ have been discarded. The figure shows that the estimates do not align along a polynomial of income as suggested by the EKC hypothesis. Indeed there appear to be no simple relation between the estimated $\beta_{2}$ and average per capita income. ${ }^{12}$

5.4. Granger causality. In this subsection we discuss Granger causality between emissions and income within the VAR model implied by the cointegration analysis of the previous subsections. We discuss the cases of $r=0,1$ and 2 in turn. We consider Granger causality only for a 1-step ahead prediction horizon. ${ }^{13}$ The asymptotic distributions of the tests in this section of a counterfactual experiment involving the long-run of the system. Here we simply interpret $\beta_{2}$ as the slope of the emissions-income relation.

${ }^{11}$ If the corresponding hypothesis implies both $\beta_{1}=\beta_{2}=0$, we relaxed the restriction on the coefficient of $x_{1 t}$ or $x_{2 t}$ with highest $p$-value in the single-coefficient significance tests.

${ }^{12}$ Regressing the estimates of $\beta_{2}$ on countries' average log GDP gave a positive slope for all chemical compounds. This contradicts the EKC expectation of an inverted $\mathrm{U}$ emissions-income relation, which is associated with a negative slope. The $t$-statistics with robust White standard errors were all insignificant. These regressions presuppose homogeneity in the emissions-income relation across countries, which may be a questionable assumption.

${ }^{13}$ The analysis for longer prediction horizons is more articulate, see Dufour et al. (2006), Omtzigt and Paruolo (2005) and Fanelli and Paruolo (2010), and goes beyond the scope of the present paper. 


\begin{tabular}{lll|ll|ll}
\hline & $\mathrm{GWP}$ & \multicolumn{2}{c}{$\mathrm{SO}_{2}$} & \multicolumn{2}{c}{$\mathrm{CO}_{2}$} \\
\hline & $W_{1}^{\Delta}$ & $W_{2}^{\Delta}$ & $W_{1}^{\Delta}$ & $W_{2}^{\Delta}$ & $W_{1}^{\Delta}$ & $W_{2}^{\Delta}$ \\
\hline \multicolumn{5}{c}{ Annex I countries in Baek } \\
\hline insignificant & 12 & 1 & 12 & 2 & 13 & 0 \\
significant & 3 & 14 & 0 & 10 & 2 & 15 \\
\hline \multicolumn{6}{c}{ non-Annex I countries in Baek } \\
\hline insignificant & 20 & 10 & 15 & 11 & 18 & 11 \\
significant & 1 & 11 & 5 & 9 & 2 & 9 \\
\hline \multicolumn{6}{c}{ Rest of the World } \\
\hline insignificant & 62 & 46 & 62 & 48 & 68 & 51 \\
significant & 7 & 23 & 8 & 22 & 4 & 21 \\
\hline \multicolumn{6}{c}{ All countries } \\
\hline insignificant & 94 & 57 & 89 & 61 & 99 & 62 \\
significant & 11 & 48 & 13 & 41 & 8 & 45 \\
\hline
\end{tabular}

TABLE 5. Granger non causality tests for $r=0$. Entries are counts. Significance level $\gamma=0.05$. $W_{1}^{\Delta}$ tests the hypothesis that income does not Grangercause emissions in growth rates. $W_{2}^{\Delta}$ tests the hypothesis that emissions do not Granger-cause income in growth rates.

are found applying the results in Johansen (1996) and Luetkepohl (2005), and they are simply stated in the following without further references.

If $r=0$, the ECM equations (4) reduce to

$$
\Delta x_{t}=\sum_{i=1}^{k-1} \Gamma_{i} \Delta x_{t-i}+\mu_{0}+\varepsilon_{t} .
$$

If the off-diagonal coefficients of $\Gamma_{i}$ are non-zero, indicated as $\Gamma_{i, h j}$ for $h \neq j=1,2$, then one has Granger-causality from $\Delta x_{j, t-i}$ to $\Delta x_{h t}$, which we call 'causality in the growth rates'. The relevant hypothesis of absence of Granger-causality in the growth rates is given by

$$
H_{0, h j}^{\Gamma}: \Gamma_{i, h j}=0, \quad i=1, \ldots, k-1 .
$$

For this hypothesis we construct a Wald test, which has a $\chi^{2}$ asymptotic distribution with $k-1$ degrees of freedom. We indicate this test as $W_{h}^{\Delta}$, to reflect that this is a Wald test for the absence of Granger-causality on $\Delta x_{h t}$ from the lagged differences $\Delta x_{j, t-i}$.

Results are summarized in Table 5. It can be seen that both directions of causality are detected and that for all country groups emissions appear to be Granger-causing income in growth rates more often than vice versa. This shows prevalence of a production function interpretation of the emissions-income relation.

If $r=1$, causality is analyzed on system (4). Similarly to the case of $r=0$, the hypothesis (8) of noncausality in the growth rates applies. However, in this case one can also have feedback from variable $x_{j, t-1}$ to $\Delta x_{h, t}$ through the $\alpha \beta^{\prime}$ matrix. In particular if

$$
H_{0 h}^{\alpha}: \alpha_{h}=0
$$




\begin{tabular}{|c|c|c|c|c|c|c|c|c|c|c|c|c|c|c|c|c|c|c|}
\hline & \multicolumn{6}{|c|}{ GWP } & \multicolumn{6}{|c|}{$\mathrm{SO}_{2}$} & \multicolumn{6}{|c|}{$\mathrm{CO}_{2}$} \\
\hline & $t_{1}$ & $t_{2}$ & $W_{1}^{\Delta}$ & $W_{2}^{\Delta}$ & $W_{1}$ & $W_{2}$ & $t_{1}$ & $t_{2}$ & $W_{1}^{\Delta}$ & $W_{2}^{\Delta}$ & $W_{1}$ & $W_{2}$ & $t_{1}$ & $t_{2}$ & $W_{1}^{\Delta}$ & $W_{2}^{\Delta}$ & $W_{1}$ & $W_{2}$ \\
\hline & \multicolumn{18}{|c|}{ Annex I countries in Baek } \\
\hline insignificant & 3 & 2 & 6 & 2 & 4 & 1 & 3 & 3 & 6 & 3 & 3 & 1 & 2 & 2 & 6 & 2 & 3 & 1 \\
\hline \multirow[t]{2}{*}{ significant } & 4 & 5 & 1 & 5 & 3 & 6 & 3 & 3 & 0 & 3 & 3 & 5 & 4 & 4 & 0 & 4 & 3 & 5 \\
\hline & \multicolumn{18}{|c|}{ non-Annex I countries in Baek } \\
\hline insignificant & 3 & 1 & 4 & 1 & 3 & 1 & 2 & 2 & 4 & 2 & 2 & 1 & 1 & 2 & 4 & 1 & 1 & 1 \\
\hline significant & 3 & 5 & 2 & 5 & 3 & 5 & 5 & 5 & 3 & 5 & 5 & 6 & 6 & 5 & 3 & 6 & 6 & 6 \\
\hline & \multicolumn{18}{|c|}{ Rest of the World } \\
\hline insignificant & 7 & 8 & 19 & 8 & 8 & 7 & 6 & 8 & 20 & 7 & 7 & 5 & 9 & 12 & 20 & 11 & 7 & 11 \\
\hline significant & 20 & 19 & 8 & 19 & 19 & 20 & 19 & 17 & 5 & 18 & 18 & 20 & 19 & 16 & 8 & 17 & 21 & 17 \\
\hline & \multicolumn{18}{|c|}{ All countries } \\
\hline insignificant & 13 & 11 & 29 & 11 & 15 & 9 & 11 & 13 & 30 & 12 & 12 & 7 & 12 & 16 & 30 & 14 & 11 & 13 \\
\hline significant & 27 & 29 & 11 & 29 & 25 & 31 & 27 & 25 & 8 & 26 & 26 & 31 & 29 & 25 & 11 & 27 & 30 & 28 \\
\hline
\end{tabular}

TABle 6. Granger non causality tests for $r=1$. Entries are counts. Significance level $\gamma=0.05 . t_{1}, W_{1}^{\Delta}, W_{1}$ are tests of hypotheses that income does not Granger-cause emissions. $t_{2}, W_{2}^{\Delta}, W_{2}$ are tests of hypotheses that emissions do not Granger-cause income.

where $\alpha=\left(\alpha_{1}, \alpha_{2}\right)^{\prime}$, then there is no causality going from $\mathrm{ecm}_{t}$ to $\Delta x_{t, h}$, and we say that $x_{h, t}$ does not adjust with respect to the equilibrium. If $\beta_{j} \neq 0$, then a test of (9) is a test of non-causality of the levels $x_{j, t-1}$ on $\Delta x_{h, t}$. We construct the associated Wald $t$-ratio, which has an asymptotically standard normal distribution. We indicate this test as $t_{h}$.

Moreover, we also consider Wald statistics for joint hypothesis (8)-(9); this test is a test of non-causality of $x_{t, j}$ in the prediction of $\Delta x_{t, h}$ when $\beta_{j} \neq 0$, and it is a test of a sufficient condition for non-causality when $\beta_{j}=0$. We indicate this test as $W_{h}$; it has an asymptotically $\chi^{2}$ distribution with $k$ degrees of freedom.

There is also a different interpretation of the hypothesis (9) in terms of the common trend in the system, based on the common trends representation in Granger's Representation Theorem. When (9) is true, the common stochastic trend is proportional to the cumulation of $\varepsilon_{h t}$, the shocks to the $h$-th equation. Hence one can interpret (9) as a test of whether shocks to income or to emissions are driving the single stochastic trend in the emissions-income system.

Results are summarized in Table 6 . It can be seen that the both directions of causality are detected. Unsurprisingly, hypothesis (9) is often rejected. The few insignificant cases allow for the interpretation in terms of driving stochastic trends discussed earlier. Both causality in the growth rates and overall causality is found to be significant in the majority of cases, for all country groups. For the $\mathrm{BI}$ and $\mathrm{BnI}$ groups there does not appear to be a preferred direction of causality. For the RoW group, one finds a slight prevalence of causality from emissions to income for GWP and $\mathrm{SO}_{2}$.

If $r=2$, causality is analyzed directly on system (3). If the off-diagonal coefficients of $A_{i}$ matrices are non-zero, indicated as $A_{i, h j}$ for $h \neq j, h, j=1,2$, then one has causality going from $x_{j, t-h}$ to $\Delta x_{h, t}$, and we say that one has 'causality in levels'. In order to test that all 


\begin{tabular}{lcc|cc|cc}
\hline & $\mathrm{GWP}$ & $\mathrm{SO}_{2}$ & \multicolumn{2}{c}{$\mathrm{CO}_{2}$} \\
\hline & $W_{1}^{2}$ & $W_{2}^{2}$ & $W_{1}^{2}$ & $W_{2}^{2}$ & $W_{1}^{2}$ & $W_{2}^{2}$ \\
\hline Annex I countries in Baek \\
\hline insignificant & 0 & 0 & 4 & 4 & 0 & 0 \\
significant & 1 & 1 & 1 & 1 & 2 & 2 \\
\hline \multicolumn{4}{c}{ non-Annex I countries in Baek } \\
\hline insignificant & 0 & 0 & 0 & 0 & 0 & 0 \\
significant & 0 & 0 & 0 & 0 & 0 & 0 \\
\hline \multicolumn{6}{c}{ Rest of the World } \\
\hline insignificant & 4 & 4 & 1 & 4 & 1 & 1 \\
significant & 3 & 3 & 3 & 0 & 0 & 0 \\
\hline \multicolumn{6}{c}{ All countries } \\
\hline insignificant & 4 & 4 & 5 & 8 & 1 & 1 \\
significant & 4 & 4 & 4 & 1 & 2 & 2 \\
\hline
\end{tabular}

TABLE 7. Granger non causality tests for $r=2$ Entries are counts. Significance level $\gamma=0.05$. $W_{1}^{2}$ tests the hypothesis that income does not Granger-cause emissions in levels. $W_{2}^{2}$ tests the hypothesis that emissions do not Grangercause income in levels.

lags of variable $j$, i.e. $x_{j, t-i}$ for $i=1, \ldots, k$, have no influence on equation for $x_{h t}$, the relevant hypothesis of non-causality is

$$
H_{0, h j}^{A}: A_{i, h j}=0, \quad i=1, \ldots, k .
$$

For this hypothesis we construct a Wald test, which we indicate as $W_{h}^{2}$ to indicate that it pertains to the case $r=2$. The test has a $\chi^{2}$ asymptotic distribution with $k$ degrees of freedom.

Results are summarized in Table 7. Only a few cases show trend-stationarity; here there does not seem to be a prevalent direction of causality.

\section{Conclusions}

The present analysis is free from many of the limitations previously encountered in the analysis of the emissions-income relation. The statistical evidence reported in the previous sections shows the presence of heterogeneity across countries and chemical compounds for the emissions-income relation. The cointegration rank, the directions of causality, and (to a lesser extent) the lag-length vary significantly. This shows the relevance of statistical methods that do not rely on the homogeneity assumption, such as the inferential tools employed in this paper.

The present approach does not suffer from simultaneity problems. In fact when we find cointegration, there is no issue of identification of the cointegrating relations, because there is only one of them. Moreover, by embedding all the analysis in a dynamical system, we can address the issue of direction of causality through appropriate statistical testing, in a unified 
modelling approach which takes advantage of the previous inference on the cointegration rank. Finally the issue of omitted variable bias is here minimized, because if emissions and income have a common trend, this property is also present when considering a group of variables which includes emissions and income, but not vice versa. In this sense common trends and cointegration are 'robust' with respect to the omission of a other variables.

The results of the analysis challenge the standard implications of the EKC hypothesis, namely that the predominant direction of causality should be from income to emissions, and that for increasing levels of income, emissions should tend to decrease. These implications are in fact at odds with the inference results in this paper on the cointegration rank and on the direction of causality between emissions and income.

The analysis of the cointegration rank is found to discriminate among several types of trends in emissions-income systems, for different countries and chemical compounds. In the majority of cases (314 out of 453) no income-emissions relation exists in levels, and the income and emissions time series are driven by two different random walks with drift. This finding is contrary to the prediction of a level relation on which the EKC is based.

In the cases where such a relation exists (40 cases for GWP, 38 for $\mathrm{SO}_{2}$ and 41 or $\mathrm{CO}_{2}$ ), the income and emissions time series are driven by the same random walk with drift. The slope coefficients estimated in these cases, however, do not align along a polynomial of average income across countries, as predicted by the EKC.

In the remaining cases ( 8 for GWP, 9 for $\mathrm{SO}_{2}$ and 3 for $\mathrm{CO}_{2}$ ) the income and emissions time series are driven by a linear trend. In this group of cases, no help can come from increasing income for the reduction of emissions in the long-run. This evidence is mostly for $\mathrm{SO}_{2}$, with 5 countries in the BI group (Belgium, Finland, Spain, Switzerland, USA).

The analysis of directions of causality reveals that both directions of causality are present; for the cases with no income-emissions relation in levels, we find a predominance of the interpretation of the emissions-income relation as a production function, which is at odds with the EKC hypothesis, which is based on a consumption function argument. Moreover, these findings are not sensitive to the activity mix underlying the emissions of different chemical compounds.

All these results challenge the plausibility of the EKC hypothesis and of its standard implication that at increasing levels of income, emissions tend to decrease. Further insights may be achieved by modelling an enlarged set of variables; this is left to future research.

\section{ACKNOWLEDGEMENTS}

Financial support from the EC-JRC is gratefully acknowledged by Ben Murphy. The authors are responsible for the analysis and for any remaining error. The opinions expressed here do not necessarily reflect the opinion of the European Commission.

\section{REFERENCES}

Ang, J. B. (2007). CO2 emissions, energy consumption, and output in France. Energy Policy $35(10), 4772-4778$. 
Baek, J., Y. Cho, and W. W. Koo (2009). The environmental consequences of globalization: A country-specific time-series analysis. Ecological Economics 68(8-9), 2255-2264.

Boswijk, H. and J. Doornik (2005). Distribution approximations for cointegration tests with stationary exogenous regressors. Journal of Applied Econometrics 20, 797-810.

Coondoo, D. and S. Dinda (2002). Causality between income and emission: a country groupspecific econometric analysis. Ecological Economics 40(3), 351 - 367.

Coondoo, D. and S. Dinda (2008). Carbon dioxide emission and income: A temporal analysis of cross-country distributional patterns. Ecological Economics 65(2), 375-385.

Davidson, J. E. H., D. F. Hendry, F. Srba, and S. Yeo (1978). Econometric modelling of the aggregate time-series relationship between consumers' expenditure and income in the united kingdom. The Economic Journal 88, 661-692.

Dufour, J., D. Pelletier, and E. Renault (2006). Short run and long run causality in time series: inference. Journal of Econometrics 132, 337-362.

EC-JRC/PBL (2011). Emission Database for Global Atmospheric Research (EDGAR), release version 4.1. Database and Technical report. Technical report, European Commission, Joint Research Centre (JRC) \& Netherlands Environmental Assessment Agency (PBL), http://edgar.jrc.ec.europa.eu.

Engle, R. and C. Granger (1987). Co-integration and Error Correction: Representation, Estimation, and Testing. Econometrica 55, 251-276.

Fanelli, L. and P. Paruolo (2010). Speed of adjustment in cointegrated systems. Journal of Econometrics 158, 130-141.

Galeotti, M., A. Lanza, and F. Pauli (2006). Reassessing the Environmental Kuznets Curve for CO2 emissions: A robustness exercise. Ecological Economics 57(1), 152-163.

Gonzalo, J. (1994). Five alternative methods of estimating long-run equilibrium relationships. Journal of Econometrics 60, 203-233.

Granger, C. W. J. and P. Newbold (1974). Spurious regressions in econometrics. Journal of Econometrics 2(2), 111 - 120.

Heston, A., R. Summers, and B. Aten (2011). Penn world table version 7.0. Technical report, Center for International Comparisons of Production, Income and Prices at the University of Pennsylvania.

Hof, A. F. and M. G. J. Den Elzen (2010). The effect of different historical emissions datasets on emission targets of the sectoral mitigation approach triptych. Climate Policy 10, 684-704.

IPCC (2006). 2006 IPCC Guidelines for National Greenhouse Gas Inventories, Volume 1 General Guidance and Reporting. Intergovernmental Panel on Climate Change.

IPCC (2007). Contribution of Working Group III to the Fourth Assessment Report of the Intergovernmental Panel on Climate Change, 200\%. Cambridge University Press.

Janssens-Maenhout, G., S. Monni, J. van Aardenne, J. G. J. Olivier, U. Doering, J. A. H. W. Peters, V. Pagliari, L. Orlandini, F. San Martin, J. Wilson, and F. Raes (2011). Edgarv4 greenhouse gas emission database: consistently covering the globe from 1970 till 2008. to be submitted to Env. Sc. Pol..

Johansen, S. (1996). Likelihood-based Inference in Cointegrated Vector Auto-Regressive Models. Oxford University Press. 
Johansen, S. (2002). A small sample correction of the test for cointegrating rank in the vector autoregressive model. Econometrica 70, 1929-1961.

Johansen, S. (2005). Interpretation of cointegrating coefficients in the cointegrated vector autoregressive model. Oxford Bulletin of Economics and Statistics 67, 93-104.

Luetkepohl, H. (2005). New Introduction to Multiple Time Series Analysis. Berlin: SpringerVerlag.

Luetkepohl, H. and M. Kratzig (2004). Applied Time Series Econometrics. Cambridge University Press.

Meehl, G., T. Stocker, W. Collins, P. Friedlingstein, A. Gaye, J. Gregory, A. Kitoh, R. Knutti, J. Murphy, A. Noda, S. Raper, I. Watterson, W. A.J., and Z.-C. Zhao (2007). Global climate projections. In S. Solomon, D. Qin, M. Manning, Z. Chen, M. Marquis, K. Averyt, T. M., and H. Miller (Eds.), Climate Change 200\%: The Physical Science Basis. Contribution of Working Group I to the Fourth Assessment Report (AR4) of the Intergovernmental Panel on Climate Change (IPCC), Chapter 10.1. Cambridge, United Kingdom and New York, NY, USA: Cambridge University Press.

Müller-Fürstenberger, G. and M. Wagner (2007). Exploring the Environmental Kuznets hypothesis: Theoretical and econometric problems. Ecological Economics 62(3-4), 648-660.

Nakićenović, N. and R. Swart (2000). Special Report on Emissions Scenarios. A Special Report of Working Group III of the Intergovernmental Panel on Climate Change. Cambridge, United Kingdom and New York, NY, USA: Cambridge University Press.

Nelson, C. and C. Plosser (1982). Trends and random walks in macroeconomic time series: Some evidence and implications. Journal of Monetary Economics 10, 139-162.

Olivier, J. and J. van Aardenne (2007). EDGAR and UNFCCC greenhouse gas datasets: comparisons as indicator of accuracy. P. Bergamaschi (ed), Atmospheric Monitoring and Inverse Modelling for Verification of National and EU and National and EU Bottom-up GHG Inventories Joint Research Center and European Commission, 87-90.

Omtzigt, P. and P. Paruolo (2005). Impact factors. Journal of Econometrics 128, 31-68.

Perman, R. and D. I. Stern (2003). Evidence from panel unit root and cointegration tests that the Environmental Kuznets Curve does not exist. Australian Journal of Agricultural and Resource Economics 47(3), 325-347.

Phillips, P. (1986). Understanding spurious regressions in econometrics. Journal of Econometrics 33(3), $311-340$.

Siebert, H. (2008). Economics of the Environment - Theory and Policy, Seventh Edition. Springer.

Stern, D. I. (2004). The rise and fall of the Environmental Kuznets Curve. World Development 32(8), 1419-1439.

Stern, D. I. (2006). An atmosphere-ocean time series model of global climate change. Computational Statistics 83 Data Analysis 51(2), 1330-1346.

Stern, D. I. (2010). Between estimates of the emissions-income elasticity. Ecological Economics $69(11), 2173-2182$.

Stern, D. I. and R. K. Kaufmann (1999). Econometric analysis of global climate change. Environmental Modelling and Software 14(6), 597 - 605. 


\begin{tabular}{lrrr}
\hline $\mathrm{CO}_{2}$ & 1970 & 2000 & 2008 \\
\hline agriculture/land-use related & $24.06 \%$ & $17.65 \%$ & $14.65 \%$ \\
products \& processes related & $4.39 \%$ & $5.14 \%$ & $6.03 \%$ \\
energy/fossil fuel related & $71.54 \%$ & $77.22 \%$ & $79.32 \%$ \\
\hline $\mathrm{SO}_{2}$ & & & \\
\hline agriculture/land-use related & $2.13 \%$ & $1.83 \%$ & $1.93 \%$ \\
products \& processes related & $16.28 \%$ & $12.17 \%$ & $13.23 \%$ \\
energy/fossil fuel related & $81.59 \%$ & $86.01 \%$ & $84.82 \%$ \\
\hline GWP & & & \\
\hline agriculture/land-use related & $34.01 \%$ & $26.40 \%$ & $22.98 \%$ \\
products \& processes related & $7.79 \%$ & $8.95 \%$ & $9.85 \%$ \\
energy/fossil fuel related & $58.20 \%$ & $64.65 \%$ & $67.18 \%$ \\
\hline
\end{tabular}

TABLE 8. Shares of activities for different chemical compounds.

Tamazian, A. and B. B. Rao (2010). Do economic, financial and institutional developments matter for environmental degradation? Evidence from transitional economies. Energy Economics 32(1), 137 - 145.

Verbeke, T. and M. De Clercq (2006). The EKC: some really disturbing Monte Carlo evidence. Environmental Modelling \& Software 21, 1447-1454.

Wagner, M. (2008). The carbon kuznets curve: A cloudy picture emitted by bad econometrics? Resource and Energy Economics 30(3), 388-408.

\section{APPENDIX}

Datasets. The data can be downloaded from the corresponding author's web site. Data sources are the following:

- GDP: Penn World Table (PWT 7.0), see Heston et al. (2011), using series rgdpl (PPP Converted GDP Per Capita - Laspeyres, derived from growth rates of c, g, i, at 2005 constant prices), accessed on 12/7/2010.

- Population: UNSTAT, http://unstats.un.org/unsd/snaama/selbasicFast.asp, accessed on $12 / 7 / 2010$.

- Emissions: 'The applied Emissions Database for Global Atmospheric Research', version v4.2 (EDGARv4.2), see http://edgar.jrc.ec.europa.eu, Janssens-Maenhout et al. (2011) and the brief description below.

The Emissions Database for Global Atmospheric Research (EDGARv4) is the result of almost 20 years experience with bottom-up emission inventories, driven by the development of scientific knowledge on emission generating processes and the scientists' and policy-makers' need for more recent information. The EDGARv4 incorporates a full differentiation of anthropogenic greenhouse gas and air pollutant emissions sources by sector: stationary combustion, road and non-road transportation, fugitive emissions from fuels, industrial non-combustion 
processes, solvent and other product use, agriculture, soils (a.o. rice cultivation, drained peatlands) and large-scale biomass burning and waste.

The emissions are modelled based on latest scientific knowledge, available global statistics, and methods recommended by IPCC. Official data submitted by the Annex I countries to the UNFCCC and to the Kyoto Protocol are used to some extent, especially regarding the control measures implemented since 1990 that are not available from international statistics. However, the emissions reported by countries are not used entirely because of the prerequisite of cross-country consistency and impartiality. For the recent years the impact of UNFCCC's Clean Development Mechanisms in developing countries to reduce GHG emissions from sources such as coal mines and landfills ( $\mathrm{CH} 4)$, nitric acid and adipid acid production (N2O) and the production of HCFC-22 (HFC-23) is included.

Emissions $(E M)$ for a country $c$, compound $x$ and year $y$ are computed as

$$
E M_{c}(y, x)=\sum_{i, j, k}\left[A D_{c, i}(y) \cdot T_{c, i, j}(y) \cdot E O P_{c, i, j, k}(y) \cdot E F_{c, i, j}(y, x) \cdot\left(1-R E D_{c, i, j, k}(y, x)\right)\right]
$$

where $i$ indexes sectors within country, $j$ indexes technologies within sector, $k$ indexes abatement measures within technology and the following definitions apply:

- $A D$ : activity data

- $T$ : technology mix factors

- EOP: end-of-pipe reduction factors

- $E F$ : (uncontrolled) emission factors

- RED: relative reduction of the uncontrolled emission by other installed abatement measure

Historical trends (1970-2008) of sector-specific activity data are given for each of the currently existing countries. The historical statistical data is subdivided to current countries in case of a country breakdown. Special attention had to be given to the industrial processes sector of the countries with Economies In Transition, in particular to former USSR and former Yugoslavia, to match the older totals for the former countries. Statistical data of microstates are often merged with the major neighborhood country (e.g. Monaco and France), along the structure of international statistics.

The technology mixes (such as share of different combustion technologies in the power-plant sector, or the fleet composition in the road transport sector), (uncontrolled) emission factors and end-of-pipe measures, are determined at different levels: country-specific, regional, country group (e.g Annex I/ Non-Annex I), or global. Other abatement measures, in particular CH4 recovery e.g. of coal mining, are determined as total gain at country level using national statistics, and in particular the national inventory reports 2008 of the Parties to UNFCCC. For those source categories and compounds where the different technologies and end-of-pipe measures are needed but can not be detailed, standard regional emission factors represent the typical technology mix. Annex 1 in Janssens-Maenhout et al. (2011) provides all details of the data sources used for the various sectors with specification of the references for the activity data, emission factors, and technologies with abatement measures.

The shares of activities for different emissions of chemical compounds are given in Table 8 . The EDGAR dataset has been analysed and compared with national estimates and with 
other global datasets in Olivier and van Aardenne (2007), Galeotti et al. (2006), and Hof and Den Elzen (2010).

Extra material: Additional tables

\begin{tabular}{lcccccc}
\hline & \multicolumn{2}{c}{$\mathrm{GWP}$} & \multicolumn{2}{c}{$\mathrm{SO}_{2}$} & \multicolumn{2}{c}{$\mathrm{CO}_{2}$} \\
\hline$H(r)$ & $r=0$ & $r \leq 1$ & $r=0$ & $r \leq 1$ & $r=0$ & $r \leq 1$ \\
\hline Australia & 0.659 & 0.693 & 0.058 & 0.406 & 0.306 & 0.542 \\
Austria & 0.008 & 0.183 & 0.013 & 0.177 & 0.008 & 0.204 \\
Belgium & 0.087 & 0.514 & 0.004 & 0.014 & 0.109 & 0.694 \\
Canada & 0.222 & 0.505 & 0.054 & 0.148 & 0.305 & 0.562 \\
Denmark & 0.186 & 0.265 & 0.291 & 0.559 & 0.144 & 0.217 \\
Finland & 0.011 & 0.166 & 0.006 & 0.037 & 0.015 & 0.153 \\
France & 0.140 & 0.551 & 0.132 & 0.710 & 0.126 & 0.490 \\
Greece & 0.000 & 0.024 & 0.001 & 0.179 & 0.000 & 0.013 \\
Iceland & 0.656 & 0.750 & 0.139 & 0.587 & 0.834 & 0.615 \\
Ireland & 0.001 & 0.383 & 0.115 & 0.402 & 0.022 & 0.393 \\
Italy & 0.067 & 0.593 & 0.436 & 0.654 & 0.079 & 0.637 \\
Japan & 0.220 & 0.719 & 0.350 & 0.832 & 0.281 & 0.846 \\
Luxembourg & 0.613 & 0.488 & 0.552 & 0.748 & 0.664 & 0.501 \\
Netherlands & 0.129 & 0.298 & 0.016 & 0.364 & 0.135 & 0.337 \\
New Zealand & 0.628 & 0.775 & 0.043 & 0.422 & 0.506 & 0.800 \\
Norway & 0.302 & 0.493 & 0.091 & 0.635 & 0.274 & 0.340 \\
Portugal & 0.001 & 0.930 & 0.006 & 0.071 & 0.001 & 0.854 \\
Spain & 0.002 & 0.052 & 0.000 & 0.003 & 0.001 & 0.025 \\
Sweden & 0.530 & 0.588 & 0.203 & 0.177 & 0.475 & 0.552 \\
Switzerland & 0.426 & 0.838 & 0.014 & 0.040 & 0.006 & 0.054 \\
Turkey & 0.002 & 0.095 & 0.015 & 0.055 & 0.091 & 0.159 \\
United Kingdom & 0.239 & 0.575 & 0.202 & 0.576 & 0.071 & 0.125 \\
United States & 0.023 & 0.664 & 0.001 & 0.011 & 0.030 & 0.750 \\
\hline & & & & & & \\
& & & 0.050
\end{tabular}

TABle 9. LR trace test p-values Annex I countries in Baek 


\begin{tabular}{|c|c|c|c|c|c|c|}
\hline \multirow[b]{2}{*}{$H(r)$} & \multicolumn{2}{|c|}{ GWP } & \multicolumn{2}{|c|}{$\mathrm{SO}_{2}$} & \multicolumn{2}{|c|}{$\mathrm{CO}_{2}$} \\
\hline & $r=0$ & $r \leq 1$ & $r=0$ & $r \leq 1$ & $r=0$ & $r \leq 1$ \\
\hline Argentina & 0.395 & 0.787 & 0.697 & 0.673 & 0.185 & 0.656 \\
\hline Bolivia & 0.552 & 0.769 & 0.827 & 0.826 & 0.757 & 0.925 \\
\hline Brazil & 0.156 & 0.536 & 0.022 & 0.923 & 0.110 & 0.451 \\
\hline Chile & 0.014 & 0.194 & 0.065 & 0.070 & 0.034 & 0.147 \\
\hline China & 0.179 & 0.577 & 0.288 & 0.746 & 0.198 & 0.651 \\
\hline Colombia & 0.577 & 0.730 & 0.826 & 0.969 & 0.576 & 0.604 \\
\hline Costa Rica & 0.150 & 0.356 & 0.289 & 0.602 & 0.794 & 0.878 \\
\hline Ecuador & 0.006 & 0.718 & 0.026 & 0.202 & 0.009 & 0.390 \\
\hline El Salvador & 0.066 & 0.136 & 0.015 & 0.354 & 0.574 & 0.833 \\
\hline Guatemala & 0.101 & 0.100 & 0.151 & 0.360 & 0.026 & 0.124 \\
\hline Honduras & 0.197 & 0.705 & 0.410 & 0.662 & 0.435 & 0.631 \\
\hline India & 0.344 & 0.877 & 0.320 & 0.865 & 0.194 & 0.589 \\
\hline Indonesia & 0.391 & 0.400 & 0.177 & 0.267 & 0.286 & 0.458 \\
\hline Israel & 0.315 & 0.963 & 0.188 & 0.274 & 0.365 & 0.959 \\
\hline Jordan & 0.002 & 0.539 & 0.037 & 0.429 & 0.001 & 0.593 \\
\hline Korea, Republic of & 0.148 & 0.722 & 0.014 & 0.818 & 0.093 & 0.817 \\
\hline Mexico & 0.496 & 0.307 & 0.001 & 0.205 & 0.020 & 0.191 \\
\hline Nicaragua & 0.812 & 0.753 & 0.788 & 0.792 & 0.008 & 0.382 \\
\hline Panama & 0.824 & 0.756 & 0.791 & 0.733 & 0.851 & 0.775 \\
\hline Paraguay & 0.183 & 0.256 & 0.488 & 0.759 & 0.510 & 0.826 \\
\hline Peru & 0.070 & 0.223 & 0.676 & 0.760 & 0.794 & 0.729 \\
\hline Philippines & 0.399 & 0.306 & 0.700 & 0.928 & 0.647 & 0.714 \\
\hline Singapore & 0.031 & 0.756 & 0.060 & 0.180 & 0.002 & 0.697 \\
\hline Sri Lanka & 0.540 & 0.704 & 0.670 & 0.745 & 0.774 & 0.696 \\
\hline Thailand & 0.032 & 0.285 & 0.079 & 0.128 & 0.355 & 0.365 \\
\hline Uruguay & 0.034 & 0.096 & 0.015 & 0.061 & 0.066 & 0.496 \\
\hline Venezuela & 0.177 & 0.519 & 0.493 & 0.448 & 0.156 & 0.426 \\
\hline
\end{tabular}

TABLE 10. LR trace test p-values non-Annex I countries in Baek. 


\begin{tabular}{lllllll}
\hline & \multicolumn{2}{c}{$\mathrm{GWP}$} & \multicolumn{2}{c}{$\mathrm{SO}_{2}$} & \multicolumn{2}{c}{$\mathrm{CO}_{2}$} \\
\hline$H(r)$ & $r=0$ & $r \leq 1$ & $r=0$ & $r \leq 1$ & $r=0$ & $r \leq 1$ \\
\hline Australia & 12.0 & 3.8 & 22.1 & 5.8 & 16.2 & 4.8 \\
Austria & 27.6 & 8.0 & 26.3 & 8.1 & 27.6 & 7.7 \\
Belgium & 20.8 & 5.0 & 29.7 & 13.8 & 20.1 & 3.8 \\
Canada & 17.5 & 5.0 & 22.3 & 8.5 & 16.2 & 4.7 \\
Denmark & 18.2 & 7.0 & 16.4 & 4.7 & 19.1 & 7.6 \\
Finland & 26.9 & 8.3 & 28.4 & 11.8 & 26.1 & 8.5 \\
France & 19.2 & 4.7 & 19.4 & 3.7 & 19.6 & 5.1 \\
Greece & 38.2 & 12.7 & 32.0 & 8.1 & 39.2 & 14.0 \\
Iceland & 12.0 & 3.4 & 19.2 & 4.5 & 9.8 & 4.3 \\
Ireland & 34.2 & 5.9 & 19.9 & 5.8 & 24.9 & 5.9 \\
Italy & 21.6 & 4.5 & 14.5 & 4.1 & 21.2 & 4.2 \\
Japan & 17.5 & 3.6 & 15.6 & 2.9 & 16.5 & 2.8 \\
Luxembourg & 12.5 & 5.2 & 13.2 & 3.4 & 11.9 & 5.1 \\
Netherlands & 19.5 & 6.7 & 25.8 & 6.1 & 19.4 & 6.3 \\
New Zealand & 12.3 & 3.3 & 23.0 & 5.6 & 13.7 & 3.1 \\
Norway & 16.2 & 5.1 & 20.7 & 4.2 & 16.6 & 6.3 \\
Portugal & 32.0 & 2.0 & 28.6 & 10.3 & 31.8 & 2.7 \\
Spain & 31.3 & 11.0 & 38.6 & 16.9 & 33.2 & 12.6 \\
Sweden & 13.4 & 4.5 & 17.9 & 8.1 & 14.0 & 4.7 \\
Switzerland & 14.6 & 2.8 & 26.1 & 11.6 & 28.3 & 10.9 \\
Turkey & 31.6 & 9.6 & 26.0 & 10.9 & 20.7 & 8.4 \\
United Kingdom & 17.2 & 4.6 & 17.9 & 4.6 & 21.5 & 9.0 \\
United States & 24.8 & 4.0 & 32.6 & 14.3 & 24.0 & 3.4 \\
\hline & & & & & &
\end{tabular}

TABLE 11. LR trace test Annex I countries in Baek. 


\begin{tabular}{|c|c|c|c|c|c|c|}
\hline \multirow[b]{2}{*}{$H(r)$} & \multicolumn{2}{|c|}{ GWP } & \multicolumn{2}{|c|}{$\mathrm{SO}_{2}$} & \multicolumn{2}{|c|}{$\mathrm{CO}_{2}$} \\
\hline & $r=0$ & $r \leq 1$ & $r=0$ & $r \leq 1$ & $r=0$ & $r \leq 1$ \\
\hline Argentina & 15.0 & 3.2 & 11.6 & 3.9 & 18.2 & 4.0 \\
\hline Bolivia & 13.2 & 3.3 & 9.9 & 2.9 & 10.9 & 2.1 \\
\hline Brazil & 18.8 & 4.8 & 24.9 & 2.1 & 20.0 & 5.4 \\
\hline Chile & 26.1 & 7.9 & 21.7 & 10.3 & 23.7 & 8.6 \\
\hline China & 18.3 & 4.6 & 16.4 & 3.5 & 18.0 & 4.1 \\
\hline Colombia & 12.9 & 3.6 & 10.0 & 1.5 & 12.9 & 4.4 \\
\hline Costa Rica & 19.0 & 6.2 & 16.4 & 4.4 & 10.4 & 2.5 \\
\hline Ecuador & 28.4 & 3.6 & 24.5 & 7.8 & 27.4 & 5.9 \\
\hline El Salvador & 21.6 & 8.7 & 25.8 & 6.2 & 12.9 & 2.9 \\
\hline Guatemala & 20.3 & 9.5 & 19.0 & 6.1 & 24.5 & 9.0 \\
\hline Honduras & 18.0 & 3.7 & 14.8 & 4.0 & 14.5 & 4.2 \\
\hline India & 15.6 & 2.5 & 16.0 & 2.6 & 18.0 & 4.5 \\
\hline Indonesia & 15.0 & 5.8 & 18.4 & 7.0 & 16.5 & 5.4 \\
\hline Israel & 16.0 & 1.6 & 18.1 & 6.9 & 15.4 & 1.7 \\
\hline Jordan & 30.5 & 4.8 & 23.5 & 5.6 & 32.9 & 4.5 \\
\hline Korea, Republic of & 19.0 & 3.6 & 26.1 & 3.0 & 20.6 & 3.0 \\
\hline Mexico & 13.8 & 6.6 & 33.9 & 7.7 & 25.2 & 7.9 \\
\hline Nicaragua & 10.2 & 3.4 & 10.5 & 3.2 & 27.5 & 5.9 \\
\hline Panama & 10.0 & 3.4 & 10.4 & 3.5 & 9.6 & 3.3 \\
\hline Paraguay & 18.3 & 7.1 & 13.9 & 3.4 & 13.7 & 2.9 \\
\hline Peru & 21.4 & 7.5 & 11.8 & 3.4 & 10.4 & 3.6 \\
\hline Philippines & 15.0 & 6.6 & 11.5 & 2.0 & 12.1 & 3.7 \\
\hline Singapore & 23.9 & 3.4 & 22.0 & 8.0 & 30.9 & 3.8 \\
\hline Sri Lanka & 13.3 & 3.7 & 11.9 & 3.5 & 10.7 & 3.8 \\
\hline Thailand & 23.9 & 6.8 & 21.1 & 8.9 & 15.5 & 6.1 \\
\hline Uruguay & 23.7 & 9.6 & 26.0 & 10.7 & 21.7 & 5.1 \\
\hline Venezuela & 18.4 & 4.9 & 13.8 & 5.5 & 18.8 & 5.6 \\
\hline
\end{tabular}

TABLE 12. LR trace test non-Annex I countries in Baek 


\begin{tabular}{|c|c|c|c|c|c|c|c|c|c|c|}
\hline & \multicolumn{3}{|c|}{ GWP } & \multicolumn{3}{|c|}{$\mathrm{SO}_{2}$} & \multicolumn{3}{|c|}{$\mathrm{CO}_{2}$} & \multirow{2}{*}{$\begin{array}{l}\text { GDP } \\
\text { average }\end{array}$} \\
\hline & $\beta_{1}$ & $\beta_{2}$ & $\beta_{D}$ & $\beta_{1}$ & $\beta_{2}$ & $\beta_{D}$ & $\beta_{1}$ & $\beta_{2}$ & $\beta_{D}$ & \\
\hline Australia & & & & & & & & & & 10.18 \\
\hline Austria & 0 & -1 & 0.02 & 0 & -1 & 0.02 & 0 & -1 & 0.02 & 10.17 \\
\hline Belgium & & & & & & & & & & 10.12 \\
\hline Canada & & & & & & & & & & 10.20 \\
\hline Denmark & & & & & & & & & & 10.16 \\
\hline Finland & -1 & -0.85 & 0.02 & & & & -1 & -1.22 & 0.03 & 10 \\
\hline France & & & & & & & & & & 10.08 \\
\hline Greece & & & & -1 & -0.86 & 0 & & & & 9.82 \\
\hline Iceland & & & & & & & & & & 10.19 \\
\hline Ireland & -1 & -0.32 & 0.02 & & & & -1 & 0 & 0.01 & 9.83 \\
\hline Italy & & & & & & & & & & 10.03 \\
\hline Japan & & & & & & & & & & 10.07 \\
\hline Luxembourg & & & & & & & & & & 10.61 \\
\hline Netherlands & & & & -1 & -4.23 & 0 & & & & 10.19 \\
\hline New Zealand & & & & -1 & 1.98 & -0.08 & & & & 9.93 \\
\hline Norway & & & & & & & & & & 10.37 \\
\hline Portugal & -1 & 2.42 & -0.04 & -1 & -3.42 & 0.11 & -1 & 3.43 & -0.06 & 9.51 \\
\hline Spain & 0 & -1 & 0.02 & & & & & & & 9.86 \\
\hline Sweden & & & & & & & & & & 10.15 \\
\hline Switzerland & & & & & & & -1 & 0 & -0 & 10.38 \\
\hline Turkey & -1 & 0.83 & 0 & -1 & 0 & 0 & & & & 8.81 \\
\hline United Kingdom & & & & & & & & & & 10.07 \\
\hline United States & 0 & -1 & 0.02 & & & & 0 & -1 & 0.02 & 10.32 \\
\hline
\end{tabular}

TABLE 13. Estimates of $\beta$ when the selected cointegration rank $r$ is equal 1; Annex I countries in Baek. 


\begin{tabular}{|c|c|c|c|c|c|c|c|c|c|c|}
\hline & \multicolumn{3}{|c|}{ GWP } & \multicolumn{3}{|c|}{$\mathrm{SO}_{2}$} & \multicolumn{3}{|c|}{$\mathrm{CO}_{2}$} & \multirow{2}{*}{$\begin{array}{l}\text { GDP } \\
\text { average }\end{array}$} \\
\hline & $\beta_{1}$ & $\beta_{2}$ & $\beta_{D}$ & $\beta_{1}$ & $\beta_{2}$ & $\beta_{D}$ & $\beta_{1}$ & $\beta_{2}$ & $\beta_{D}$ & \\
\hline Argentina & & & & & & & & & & 9.05 \\
\hline Bolivia & & & & & & & & & & 8.04 \\
\hline Brazil & & & & -1 & -1.55 & 0 & & & & 8.77 \\
\hline Chile & -1 & 1.98 & -0.05 & & & & -1 & 1.96 & -0.04 & 8.76 \\
\hline China & & & & & & & & & & 7.30 \\
\hline Colombia & & & & & & & & & & 8.46 \\
\hline Costa Rica & & & & & & & & & & 9 \\
\hline Ecuador & -1 & 0 & 0.01 & -1 & 0 & 0 & -1 & 0 & 0.02 & 8.51 \\
\hline El Salvador & & & & -1 & 5.17 & -0.02 & & & & 8.47 \\
\hline Guatemala & & & & & & & -1 & 4.55 & 0 & 8.54 \\
\hline Honduras & & & & & & & & & & 8.03 \\
\hline India & & & & & & & & & & 7.23 \\
\hline Indonesia & & & & & & & & & & 7.66 \\
\hline Israel & & & & & & & & & & 9.82 \\
\hline Jordan & -1 & 1.48 & 0 & 0 & -1 & 0.04 & -1 & 1.58 & 0 & 8.26 \\
\hline Korea, Republic of & & & & -1 & 4.38 & -0.26 & & & & 9.18 \\
\hline Mexico & & & & 0 & -1 & 0 & -1 & 0 & 0 & 9.11 \\
\hline Nicaragua & & & & & & & 0 & -1 & -0.02 & 7.87 \\
\hline Panama & & & & & & & & & & 8.65 \\
\hline Paraguay & & & & & & & & & & 8.10 \\
\hline Peru & & & & & & & & & & 8.55 \\
\hline Philippines & & & & & & & & & & 7.65 \\
\hline Singapore & -1 & 3.11 & -0.11 & & & & -1 & 3.46 & -0.13 & 9.95 \\
\hline Sri Lanka & & & & & & & & & & 7.56 \\
\hline Thailand & 0 & -1 & 0.04 & & & & & & & 8.24 \\
\hline Uruguay & 0 & -1 & 0.02 & 0 & -1 & 0.02 & & & & 8.80 \\
\hline Venezuela & & & & & & & & & & 9.09 \\
\hline
\end{tabular}

TABLE 14. Estimates of $\beta$ when the selected cointegration rank $r$ is equal 1 ; non-Annex I countries in Baek. 


\begin{tabular}{|c|c|c|c|c|c|c|}
\hline & \multicolumn{2}{|c|}{ GWP } & \multicolumn{2}{|c|}{$\mathrm{SO}_{2}$} & \multicolumn{2}{|c|}{$\mathrm{CO}_{2}$} \\
\hline & $W_{1}^{\Delta}$ & $W_{2}^{\Delta}$ & $W_{1}^{\Delta}$ & $W_{2}^{\Delta}$ & $W_{1}^{\Delta}$ & $W_{2}^{\Delta}$ \\
\hline Australia & 0 & 1 & 0 & 1 & 0 & 1 \\
\hline \multicolumn{7}{|l|}{ Austria } \\
\hline Belgium & 0 & 1 & & & 0 & 1 \\
\hline Canada & 0 & 1 & 0 & 0 & 0 & 1 \\
\hline Denmark & 0 & 1 & 0 & 1 & 0 & 1 \\
\hline \multicolumn{7}{|l|}{ Finland } \\
\hline France & 0 & 1 & 0 & 1 & 0 & 1 \\
\hline \multicolumn{7}{|l|}{ Greece } \\
\hline Iceland & 0 & 1 & 0 & 1 & 0 & 1 \\
\hline Ireland & & & 0 & 1 & & \\
\hline Italy & 0 & 1 & 0 & 1 & 0 & 1 \\
\hline Japan & 1 & 1 & 0 & 0 & 1 & 1 \\
\hline Luxembourg & 0 & 1 & 0 & 1 & 0 & 1 \\
\hline Netherlands & 0 & 1 & & & 0 & 1 \\
\hline New Zealand & 1 & 1 & & & 0 & 1 \\
\hline Norway & 0 & 1 & 0 & 1 & 0 & 1 \\
\hline \multicolumn{7}{|l|}{ Portugal } \\
\hline \multicolumn{7}{|l|}{ Spain } \\
\hline Sweden & 0 & 1 & 0 & 1 & 0 & 1 \\
\hline Switzerland & 0 & 1 & & & & \\
\hline Turkey & & & & & 0 & 1 \\
\hline United Kingdom & 1 & 0 & 0 & 1 & 1 & 1 \\
\hline United States & & & & & & \\
\hline
\end{tabular}

TABLe 15. Granger non causality tests for $r=0$, Annex I countries in Baek. Entries equal to 0 indicate insignificant statistics, entries equal to 1 significant statistics at $\gamma=0.05$ level. $W_{1}^{\Delta}$ tests the hypothesis that income does not Granger-cause emissions in growth rates. $W_{2}^{\Delta}$ tests the hypothesis that emissions do not Granger-cause income in growth rates. 


\begin{tabular}{|c|c|c|c|c|c|c|}
\hline & \multicolumn{2}{|c|}{ GWP } & \multicolumn{2}{|c|}{$\mathrm{SO}_{2}$} & \multicolumn{2}{|c|}{$\mathrm{CO}_{2}$} \\
\hline & $W_{1}^{\Delta}$ & $W_{2}^{\Delta}$ & $W_{1}^{\Delta}$ & $W_{2}^{\Delta}$ & $W_{1}^{\Delta}$ & $W_{2}^{\Delta}$ \\
\hline Argentina & 0 & 0 & 0 & 0 & 0 & 0 \\
\hline Bolivia & 0 & 0 & 0 & 0 & 0 & 0 \\
\hline Brazil & 0 & 0 & & & 1 & 0 \\
\hline Chile & & & 1 & 0 & & \\
\hline China & 1 & 1 & 1 & 1 & 1 & 1 \\
\hline Colombia & 0 & 1 & 0 & 1 & 0 & 1 \\
\hline Costa Rica & 0 & 0 & 1 & 0 & 0 & 0 \\
\hline \multicolumn{7}{|l|}{ Ecuador } \\
\hline El Salvador & 0 & 1 & & & 0 & 0 \\
\hline Guatemala & 0 & 0 & 0 & 0 & & \\
\hline Honduras & 0 & 0 & 0 & 0 & 0 & 0 \\
\hline India & 0 & 1 & 0 & 1 & 0 & 1 \\
\hline Indonesia & 0 & 1 & 0 & 1 & 0 & 1 \\
\hline Israel & 0 & 1 & 0 & 1 & 0 & 1 \\
\hline \multicolumn{7}{|l|}{ Jordan } \\
\hline Korea, Republic of & 0 & 1 & & & 0 & 1 \\
\hline Mexico & 0 & 1 & & & & \\
\hline Nicaragua & 0 & 0 & 0 & 0 & & \\
\hline Panama & 0 & 1 & 1 & 1 & 0 & 1 \\
\hline Paraguay & 0 & 0 & 0 & 0 & 0 & 0 \\
\hline Peru & 0 & 1 & 0 & 0 & 0 & 0 \\
\hline Philippines & 0 & 0 & 0 & 0 & 0 & 0 \\
\hline Singapore & & & 0 & 1 & & \\
\hline Sri Lanka & 0 & 1 & 0 & 1 & 0 & 1 \\
\hline Thailand & & & 1 & 1 & 0 & 1 \\
\hline Uruguay & & & & & 0 & 0 \\
\hline Venezuela & 0 & 0 & 0 & 0 & 0 & 0 \\
\hline
\end{tabular}

TABle 16. Granger non causality tests for $r=0$, non-Annex I countries in Baek. Entries equal to 0 indicate insignificant statistics, entries equal to 1 significant statistics at $\gamma=0.05$ level. $W_{1}^{\Delta}$ tests the hypothesis that income does not Granger-cause emissions in growth rates. $W_{2}^{\Delta}$ tests the hypothesis that emissions do not Granger-cause income in growth rates. 


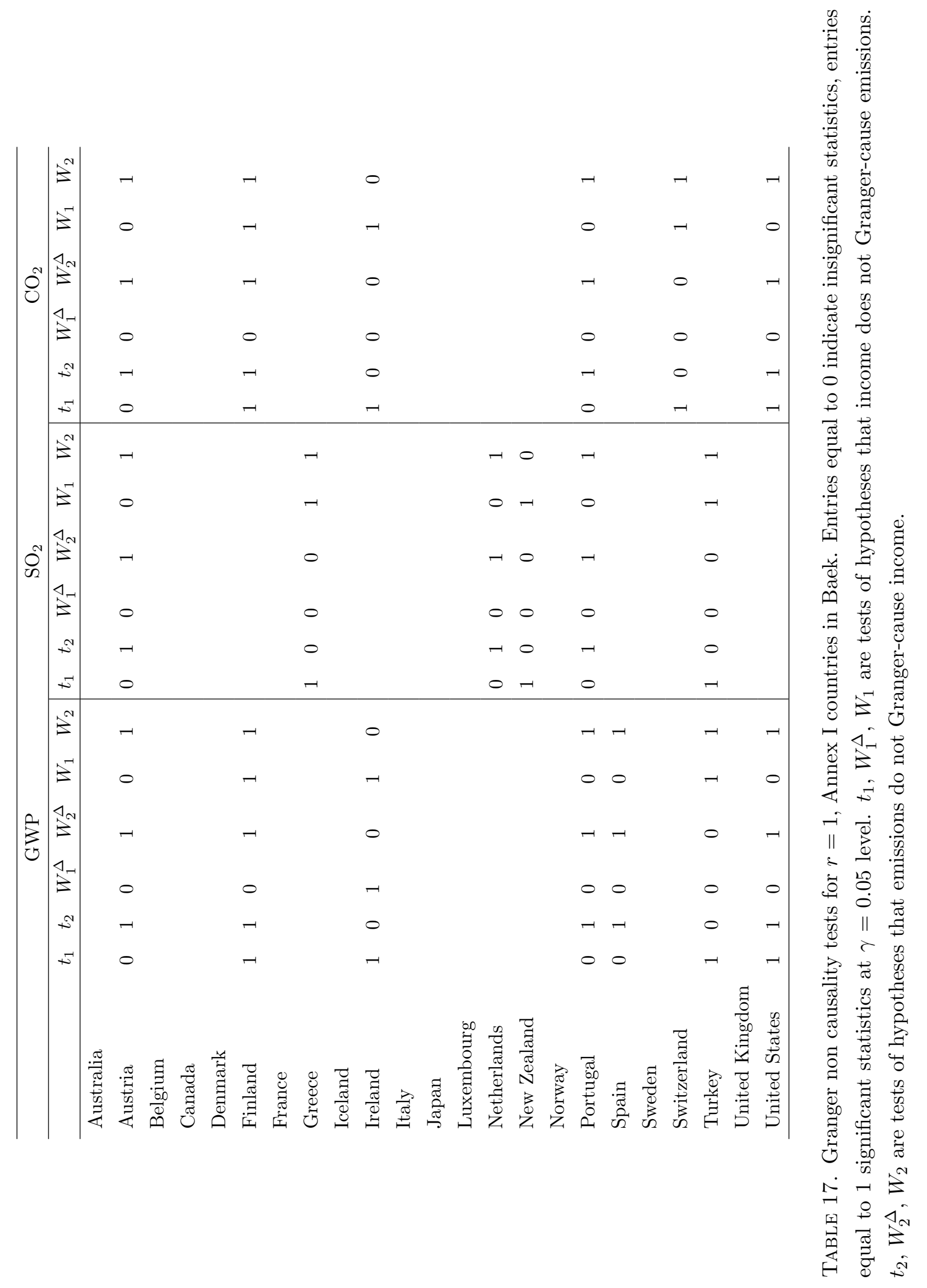



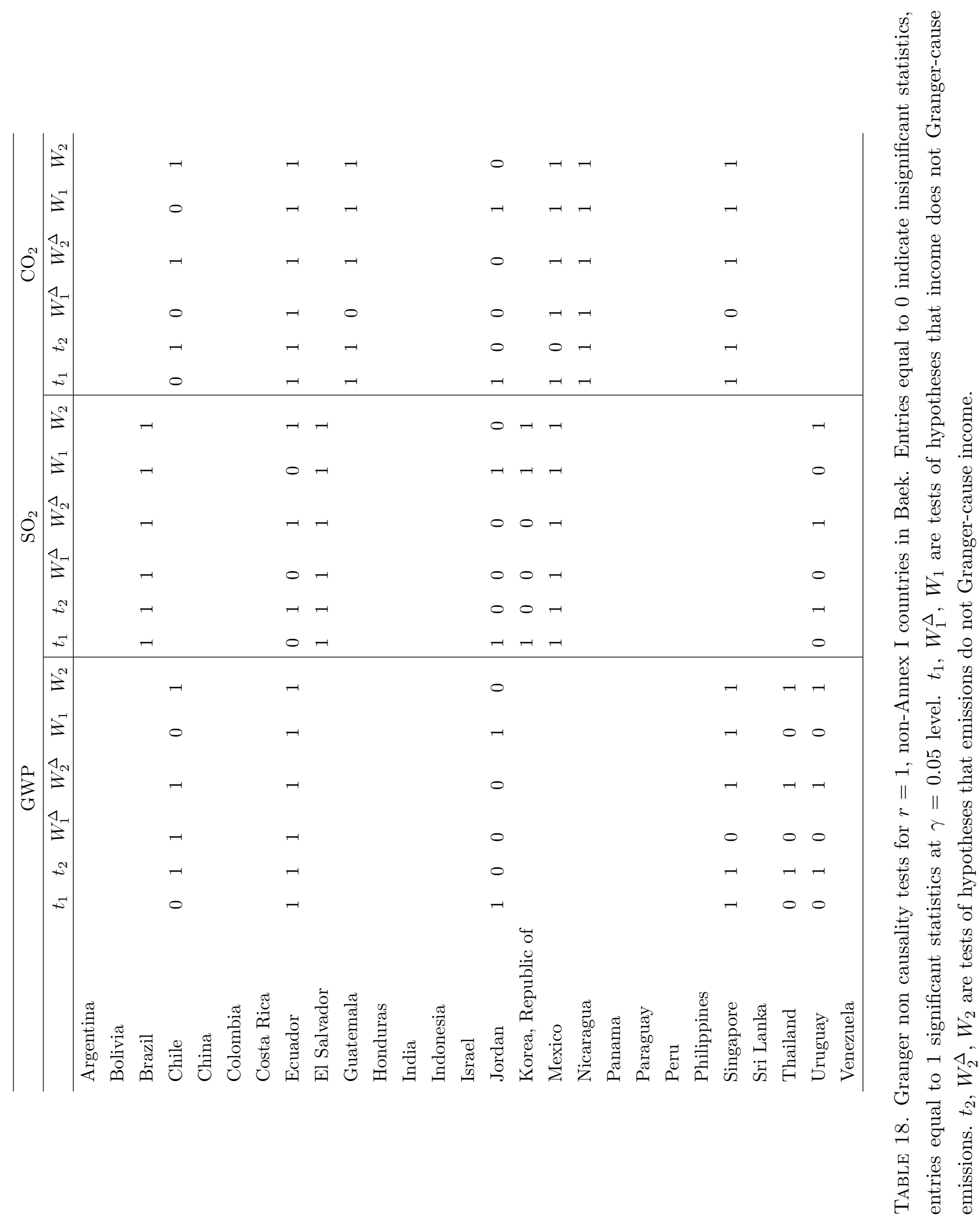


\begin{tabular}{|c|c|c|c|c|c|c|}
\hline & \multicolumn{2}{|c|}{ GWP } & \multicolumn{2}{|c|}{$\mathrm{SO}_{2}$} & \multicolumn{2}{|c|}{$\mathrm{CO}_{2}$} \\
\hline & $W_{1}^{2}$ & $W_{2}^{2}$ & $W_{1}^{2}$ & $W_{2}^{2}$ & $W_{1}^{2}$ & $W_{2}^{2}$ \\
\hline Australia & & & & & & \\
\hline Austria & & & & & & \\
\hline Belgium & & & 0 & 0 & & \\
\hline Canada & & & & & & \\
\hline Denmark & & & & & & \\
\hline Finland & & & 0 & 0 & & \\
\hline France & & & & & & \\
\hline Greece & 1 & 1 & & & 1 & 1 \\
\hline Iceland & & & & & & \\
\hline Ireland & & & & & & \\
\hline Italy & & & & & & \\
\hline Japan & & & & & & \\
\hline Luxembourg & & & & & & \\
\hline Netherlands & & & & & & \\
\hline New Zealand & & & & & & \\
\hline Norway & & & & & & \\
\hline Portugal & & & & & & \\
\hline Spain & & & 1 & 1 & 1 & 1 \\
\hline Sweden & & & & & & \\
\hline Switzerland & & & 0 & 0 & & \\
\hline Turkey & & & & & & \\
\hline United Kingdom & & & & & & \\
\hline United States & & & 0 & 0 & & \\
\hline
\end{tabular}

TABle 19. Granger non causality tests for $r=2$, Annex I countries in Baek. Entries equal to 0 indicate insignificant statistics, entries equal to 1 significant statistics at $\gamma=0.05$ level. $W_{1}^{2}$ tests the hypothesis that income does not Granger-cause emissions in levels. $W_{2}^{2}$ tests the hypothesis that emissions do not Granger-cause income in levels.

\begin{tabular}{lrrrr}
\hline & $\zeta_{i}$ & $t_{\zeta_{i}}$ & $P\left(t<t_{\zeta_{i}}\right)$ & observations \\
\hline GWP & 0.28 & 1.53 & 0.93 & 21 \\
SO2 & -0.25 & -0.35 & 0.36 & 17 \\
CO2 & 0.08 & 0.30 & 0.62 & 20 \\
\hline
\end{tabular}

TABLE 20. Cross-section regression of $\beta_{2}$ estimates on average log GDP and a constant, by chemical compound. $\zeta_{i}$ is the coefficient of average log GDP in the regression of chemical compound $i$. White Heteroskedasticity-robust standard errors. 